Post-print of Scandinavian Journal of Forest Research

DOI: http://dx.doi.org/10.1080/02827581.2014.919352.

Running head: "Determining selection cutting intensities"

\title{
Determining suitable selection cutting intensities based on long term observations on above-ground forest carbon, growth, and stand structure in Changbai Mountain, Northeast China
}

Yang Liu ${ }^{\mathrm{a}}$, Juan A. Blanco ${ }^{\mathrm{b}}$, Xiaohua Wei ${ }^{\mathrm{c}}$, Xingang Kang ${ }^{\mathrm{a}}$, Weifeng Wang ${ }^{\mathrm{d}}$, Yanrong Guo ${ }^{\mathrm{e}}$

${ }^{a}$ Key Laboratory for Silviculture and Conservation of Ministry of Education, Beijing Forestry University, Beijing 100083, China

E-mail: Yang Liu: ly9810@163.com; Xingang Kang: xingangkang@163.com

${ }^{\mathrm{b}}$ Departamento de Ciencias del Medio Natural, Universidad Pública de Navarra, Campus de Arrosadía, Pamplona, Navarra, 31013, Spain

E-mail: juan.blanco@unavarra.es

${ }^{\mathrm{c}}$ Department of Earth and Environmental Sciences, University of British Columbia (Okanagan), 3333 University Way, Kelowna, British Columbia V1V 1V7, Canada

E-mail: adam.wei@ubc.ca

${ }^{\mathrm{d}}$ College of Forestry, Jiangxi Agriculture University, Nanchang 330045, China

E-mail: wang.wf1985@163.com

${ }^{\mathrm{e}}$ College of Information Science and Technology, Beijing Forestry University, Beijing 100083, China E-mail: gyr163@163.com

Corresponding author: Xingang Kang

Key Laboratory for Silviculture and Conservation of Ministry of Education, Beijing Forestry University, No. 35, Qinghua East Road, Haidian District, Beijing 100083, China

Tel: + 8615201681189

Fax: + $861062338246-426$

E-mail: xingangkang@163.com

\section{Acknowledgements}

This study was funded by the 948 Project of State Forestry Administration (2013-4-66), Forestry Public Welfare Industry Research Item (No.200804027; 201104006) and Key Projects in the National Science and Technology Pillar Program during the Twelfth Five-year Plan Period 
(2012BAD22B02-3). This study also has received the support from the Chinese Academy of Sciences Strategic Project (XDA05060101). The authors declare that they have no conflict of interests. Great thanks are extended to Mr.Yan Gao, Mr.Qixiang Feng, Mr. Dongning Zhao, Mr. Bin Wang and all Jingouling forest farmers for their help in maintaining the permanent sub plots and taking part in the field measurement in Wangqing Forestry Bureau, Jilin Province. We would also like to thank all anonymous reviewers.

\begin{abstract}
We studied the effects of different cutting intensities $(0 \%, 5-10 \%, 15 \%$, and $20 \%$ basal area removal) on stand growth, structure, and net carbon storage in spruce-fir (Picea asperata Mast.-Abies fabri Mast. Craib) and broadleaf mixed forests on Changbai Mountain (Northeast China) over 19 years. At this site, inventory-based low-intensity selection cutting was used to maintain a continuous forest canopy. After two cutting events, results showed significant differences in growth, structure, and carbon storage among cutting intensities. When increasing cutting intensity, the growth rate of average diameter, basal area, and volume significantly increased, with the highest increment rates found in the plots with $20 \%$ basal area removal. Tree diameters for all plots showed a roughly inverse J-shaped distribution before cutting and a left-skewed unimodal distribution after two cuttings. Volume ratio (the relative amount of volume contained in different diameter classes) for small (6-14 $\mathrm{cm})$, medium $(14-26 \mathrm{~cm})$, large $(26-36 \mathrm{~cm})$, and very large $(>38 \mathrm{~cm})$ diameters remained unchanged in the plots with 5 and $10 \%$ basal area removal, but increased in the plots with 15 and $20 \%$ basal area removal, reaching approximately a 1:2:3:4 ratio in the plots with $20 \%$ basal area removal after two selection cuttings. Net carbon storage increased when increasing cutting intensity, reaching maximum storage in the plots with $20 \%$ basal area removal (cutting intensity and net $\mathrm{C}$ storage increase: $0 \%$, 7.21 Mg C ha ${ }^{-1}, 5-10 \%: 11.68 \mathrm{Mg} \mathrm{C} \mathrm{ha}^{-1}, 15 \%: 21.41 \mathrm{Mg} \mathrm{C} \mathrm{ha}^{-1}, 20 \%: 26.47 \mathrm{Mg} \mathrm{C}^{-1}$ ). Therefore, our results show the potential of low-intensity selection cutting to meet demands of both timber production and maintenance of forest cover for biodiversity values.
\end{abstract}

Keywords: close-to-nature forestry; continuous-canopy forestry; long-term research; Manchurian mixed forests; net carbon storage; selection cutting; spruce-fir forests; uneven-aged management. 


\section{Introduction}

The Changbai Mountain range is situated in the border area between China, Russia and North Korea. The forests in Changbai Mountain in northeast China are a national key forest area (Zhao et al. 2011) and have an important strategic position in ecological services and the forestry industry in eastern Asia (Shao et al. 2005). The demand for timber has increased over the past decades; hence many of the forests in the region have been harvested, mainly with clearcutting. However, serious problems concerning the use of clearcutting have emerged. For example, forest landscapes (Shao \& Zhao 1998), forest ecosystem quality (Shao et al. 2001), and the age structure of the remaining forests (Zhao \& Shao 2002) have been altered. Forest productivity and soil fertility have declined (Li \& Zhou 2000; State Forestry Administration of China 2009), and diversity has been reduced with single species forests becoming dominant (Jalonen \& Vanha-Majamaa 2001; Heinrichs \& Schmidt 2009). These issues persuaded the Chinese government to change the forestry harvesting policy to restricted logging and protection of natural forests (Shao et al. 2005). Several silvicultural methods have been developed to reduce the ecological impacts of clearcutting (Kimmins 1997). Since the 1990s, new forest policies have proposed that forests should be harvested by a more close-to-nature forestry, incorporating practices such as using inventory-based low-intensity selection cutting (Dai et al. 2009).

Inventory-based low-intensity selection cutting (also called in early literature "control method", see below) is a type of forest management designed for multi-species, uneven-aged forests. This method implies a continuous and sustainable tree-by-tree treatment, maintaining the demographic equilibrium (Schütz et al. 2012), and it is part of a close-to-nature forestry for continuous canopy cover. This method basically consists of a series of surveys at regular time intervals to characterize forest structure. After each survey, trees are selected for cutting in a way that the natural diameter distribution is maintained, 
adjusting the stand diameter and volume growth to keep a stable and complex stand structure (Yu 1995). The main objective of this method is to simulate a more natural, close-to-nature low-disturbance regime (Heinrichs \& Schmidt 2009). Hence, the control method is a low-impact silviculture, always harvesting $20 \%$ or less of basal area present in the stand to prevent excess canopy opening and windthrow damage that usually occur when removing higher proportions of basal area (Leibundgut 1966; Yu et al. 1996). Cutting takes place across the entire range of diameters to maintain a balanced stem distribution (OMNR 2004; Holmes et al. 2012).

Selection cutting is therefore a main component of the inventory-based low-intensity harvesting method. It is regarded as a major tool for achieving the multi-value goals of timber production and species composition on a sustainable basis (Dannenmann et al. 2007; Wu et al. 2011). Advantages of selection cutting include: 1) protected growing site for seedlings with little exposure to wind and insolation, 2) continuous seed supply for regeneration, good natural regeneration of shade tolerant species, 3) continuous flow of high quality timber, and 4) provision of continuous cover for many wildlife species (Robertson \& Myketa 1998). The effects of selection cutting on different forest features have long been a focus of research, with research topics including: 1) timber production under different selection approaches (Moore et al. 2012; Hao et al. 2005); 2) forest structure (Angers et al. 2005; Montes et al. 2005; Ciancio et al. 2006); 3) forest net productivity and biomass accumulation (Dyer et al. 2010); 4) tree and understory regeneration (Garber et al. 2011); 5) shrub and herb layer compositions after conversion of even-aged into mixed stands (Heinrichs \& Schmidt 2009), 6) species diversity (Castro-Luna et al. 2011; Boncina et al. 2007); and 7) wildlife habitat (Doyon et al. 2005; Holmes et al. 2012). Furthermore, the differences in ecological effects of different types of selection cutting have also been researched, such as group selection cutting (Kató \& Mülder 1998), and single tree selection cutting

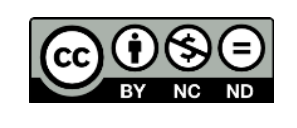


(Forget et al. 2007; Gronewold et al. 2010). Group selection cutting has been compared with single tree selection cutting and uncut reference stands (Falk et al. 2010). In addition, studies have been carried out comparing low, medium, and high selection cutting intensities (Bohn et al. 2011). These authors concluded that selection cutting could in the long-term be more productive that diameter-limit cutting.

The "control method" was applied for the first time by Henry Biolley in 1890 in the Couvet public forest (Benecke 1996; Schütz et al. 2012). Subsequently, inventory-based low-intensity selection cutting has been applied in several European countries (Schütz et al. 2012). However, this method is not widely implemented in Asia, where it has been used only in Japan (Yasuda et al. 2013), and China (Yu et al. 1996). In the mixed forests of northern Japan, the ideal cutting intensity for timber production under this method was established as $14 \%$ basal area removal (Watanabe 1985a; 1985b). In China, inventory-based low-intensity selection cutting was first introduced by Yu and his coworkers in 1987 in the spruce-fir mixed forests on Changbai Mountain. In 1996, the effects of this method were evaluated for the first time in a Chinese forest. The results showed that the stand volume increased and that low-intensity selection cutting could be more productive than clear cutting in the same conditions (Yu et al. 1996). However, this was just an initial assessment, as information on the long-term effects of selection cutting on the Manchurian mixed forests is mostly non-existent.

The Manchurian temperate mixed conifer-broadleaf forest is a unique ecosystem, being the most productive in northeastern China but also the most biodiversity rich. It provides habitat for iconic wildlife species such as the Siberian tiger (Panthera tigris altaica Temminck) or the North China leopard (Panthera pardus japonensis Gray). This ecosystem, however, is endangered by unsustainable forest management practices, and as a consequence there have been calls for a more nature-driven 
ecosystem-based forest management in the region (Yang \& Xu 2003). Adopting low-intensity management through the operational implementation of the control method in Changbai Mountain forests could be a step into such direction, but more information is needed on the long-term ecological effects of this practice. In addition, mixed forests in Northeastern China has been identified as the most $\mathrm{C}$ rich in the country, highlighting the importance for regional $\mathrm{C}$ balances of sustainably managing this forest type (Wang et al. 2014).

Because Yu et al.'s (1996) results were based on a relatively short data series (5 years after implementation of selection cuttings), it is necessary to reassess their initial results with the 19 years of data available now. This will allow for a more detailed evaluation of the effects of inventory-based low-intensity selection cutting in long-term forest attributes at these forests. As a consequence, the overall aim of this study was to analyze the effects of different selection cutting intensities $(5 \%, 10 \%$, $15 \%$, and $20 \%$ basal area removal) on stand growth, structure change, and net carbon (C) storage to determine the most suitable selection cutting intensity, compared with unmanaged control plots. The specific objectives were to compare: 1) the annual increment rates of average diameter, basal area, and volume; 2) the diameter distribution and volume ratio of different diameter classes (proportion of total volume generated by each diameter class); and 3) the net $\mathrm{C}$ storage of forest and different components in plots under different selection cutting intensities.

\section{Materials and Methods}

\section{Study area}

The study area is located in the Jingouling Experimental Forest Farm (Jilin Province), situated in the middle lower hilly region of Changbai Mountain in northeastern China (Lei et al. 2007; Figure 1). The

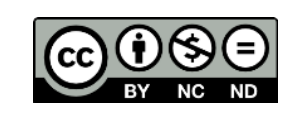


geographical range of the study area is $130^{\circ} 5^{\prime}-130^{\circ} 20^{\prime} \mathrm{E}$, and $43^{\circ} 17^{\prime}-43^{\circ} 25^{\prime} \mathrm{N}$. The climate of Changbai Mountain is alpine monsoon in the temperate zonal continent. Between 300 and 1,200 m.a.s.l., the annual precipitation ranges from 600 to $700 \mathrm{~mm}$ and the annual average relative humidity is $66 \%$. The wet season is June to August, and a relatively dry season lasts from September to May (Dai et al. 2011). The mean annual temperature is $3.9^{\circ} \mathrm{C}$ and the mean monthly maximum and minimum temperatures are 22 and $-32^{\circ} \mathrm{C}$ in July and January, respectively. The growth period is 120 days. The climate, altitude and terrain conditions support four vertically distributed soil types including, from bottom to top, dark brown forest soil (700-1600 m.a.s.l.); mountain brown coniferous forest soil (1100-1700 m.a.s.l.). The soil type of the research area is a dark brown forest soil with an average thickness of $\sim 40 \mathrm{~cm}$ ( FAO soil classification; Editorial Committee of Jilin Forest 1988). Slopes in the region are moderate $\left(5^{\circ}\right.$ to $\left.25^{\circ}\right)$. The main forest types include spruce-fir dominated mixed coniferous forests, birch-aspen mixed broad leaved forests and plantations consisting of larch, spruce, fir and pine. The main species include spruce (Picea asperata), fir (Abies fabri), Korean pine (Pinus koraiensis Siebold \& Zucc.), birch (Betula costata Trautv.) and linden (Tilia amurensis Rupr.). In this region, selection cutting intensities usually range from 5 to $20 \%$ of total density, and the cutting cycle from 5 to 10 years (Kang et al. 2003; Kang 2011), following the guidelines for low intensity selection cutting in multistoried, uneven aged, spruce-fir dominated mixed (Jian et al. 2006). The Chinese guidelines are a local adaptation of North-American guidelines such as OMNR (2004), and they state that selection cutting intensity must be $20 \%$ of basal area or less, it must retain a minimum stand volume of $110 \mathrm{~m}^{3}$ $\mathrm{ha}^{-1}$ and the canopy openness after cutting must be 0.5 or lower.

\section{Experimental design}

Representative woodlands were chosen to set the plots for testing the inventory-based low-intensity 
selection cutting in Changbai Mountain. Experimental plots were grouped in two blocks (Figure 1). Site condition was the same for all plots, with average tree age of $70 \pm 20$ years (ranging between 32 and 145 minimum and maximum ages, respectively). Block I was established in 1987 with an area of 95.2 ha and Block II was established in 1988 with an area of 110.0 ha. Each plot was subdivided into square-shaped sub-plots with 0.04 ha surface (112 in Block I and 162 in Block II). Spacing between consecutive sub-plots was $90 \mathrm{~m}$. Sub-plot line boundaries were cleared from understory and marked with red paint. A cement stake was laid and numbered in the center of each sub-plot. All trees on each sub-plot with diameter at breast height $(\mathrm{DBH})$ above $5 \mathrm{~cm}$ were numbered and tagged for repeated diameter measurements. The 274 sub plots were continuously observed for 19 years from 1987 to 2006 (See Annex 1 for a detailed calendar of activities). The experimental design consisted of control plus four cutting treatments (cutting intensity levels $0 \%, 5 \%, 10 \%, 15 \%$, and $20 \%$ of basal area removal, the range recommended for low-intensity selection cutting) randomly assigned to the experimental plots. There were two replicates for the lowest intensities (5\% and $10 \%$ basal area removal) and three replicates for the $0 \%$ and the highest intensities (15\% and $20 \%$ basal area removal) (Figure 1).

Selection cutting was applied in all the experimental plots in both blocks first in 1990 and a second time in 1995 (see Annex 1). To reduce tree and environmental damage selection cutting was implemented in winter, when forest floor was more protected due to ice and snow. In order to reduce the injuries to the retention trees, logs were centralized and transported to both sides of the skidding road by animals, and then the logs were transported together to the wood depot by animal and small tractor skidding. Finally, for safety as well as environmental conditions trees selected for cutting were not linked to other trees harvested and operators had special care in keeping as many saplings untouched as possible. 


\section{Data measurement and statistical analysis}

DBH of all trees with diameter above $5 \mathrm{~cm}$ was measured to the nearest $0.1 \mathrm{~cm}$ every 2 or 3 years with a diameter tape. The following indicators were calculated at each plot: plot average DBH, basal area, volume and growth rate, number of trees, volume of trees in each diameter class, and net $\mathrm{C}$ storage of each plot. A Wilcoxon Rank-sum Test (Heiri et al. 2009) was conducted to test the change in distribution shape of the stand diameter distributions between the initial and final inventories. R statistical software (http://www.r-project.org) was used for Wilcoxon Rank-sum Test and fitting of the diameter distribution parameters (Streitberg \& Röhmel 1986).

Measure of the efficiency of blocking indicated that blocking was not needed, so blocks were not considered in the statistical analyses (Lentner et al. 1989; Newman et al. 1997; Quinn \& Keough 2002). Therefore, univariate ANOVA (cutting intensity as a factor) was used to analyse statistical differences among cutting intensities for diameter, basal area, volume, carbon storage, and annual increments for all these variables (except for carbon storage). Before data analyses, boxplots and histograms were used to detect possible outliers and to determine the skewness of the data. Differences among groups were tested with Tukey HSD. A p-value of 0.05 or less was defined as statistically significant. ANOVAs were carried out using SPSS v18.

\section{Measurement of changes in stand growth}

Annual increments in tree dimensional variables illustrate the speed of tree growth processes in a certain period, and they are a measure of change in stand attributes over time. Annual increments were calculated for each plot with equation (1) for each measurement period (Brown et al. 1988):

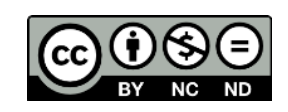


$Z(t)=\left(y_{t}-y_{t-n}\right) / n$,

where $Z(t)=$ Annual increment; $n=$ the number of years between inventories; $y_{t}=$ variable (diameter, basal area or volume) in inventory $t$ (at the end of the interval) and $y_{t-n}=$ variable in inventory $t-n$ (at the beginning of the interval).

\section{Measurement of changes in stand structure}

\section{Changes in diameter distribution}

The Weibull distribution function, which has a strong adaptability and high flexibility, was chosen to fit stand diameter distributions. Parameters $b$ and $c$ of the Weibull function were used to explain the change in tree diameter distribution in each plot. The complete three parameter probability density function for the Weibull distribution (Weibull \& Sweden 1951) is defined as follows:

$f(x)=c / b[(x-a) / b]^{c-1} \exp [-(x-a) / b]^{c}$,

where $f(x)$ is the density of trees with the size $x(0 \leq x) ; x$ is the DBH; $a$ is the location parameter; $b$ is the scale parameter; and $c$ is the shape parameter. In diameter distribution functions, $a$ is the lower limit value of minimum diameter class, which $=5 \mathrm{~cm}$ in this study. The maximum likelihood method was used to estimate the parameters of the Weibull distribution (SAS 1999; Liu et al. 2009). It has been described that the parameters $b$ and $c$ of the Weibull distribution function correlate well with the stand attributes (Meng 2006; Merganič \& Sterba 2006). Parameter $b$, which has a close linear positive correlation with the stand average diameter, reflects the distribution scope. Parameter $c$ determines the

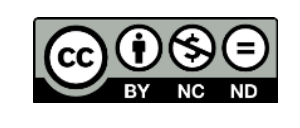


shape of the diameter distribution curve. If $c<1$, the function has an inversed J-shape. If $c<3.6$, the Weibull density function is bell shaped and left-skewed.

\section{Changes in ratios of diameter classes}

To study stand volume, trees were divided into four different diameter classes, following the standard set by the Chinese Ministry of Forestry. Diameter classes were: small $(6-14 \mathrm{~cm})$, medium $(14-26 \mathrm{~cm})$, large (26-36 cm), and very large (>38 cm) (Ministry of Forestry of P. R. China 1996). To study the impact of low intensity selection cutting on stand volume ratio for each diameter class, the volume of each class was separately calculated according to the diameter class size for each period. The volume of individual trees in diameter $D$ was estimated based on a one-parameter volume formula as shown in Table 1 (Heilongjiang's Department of Inventory and Management of Forest Resource 1971; Ministry of Agriculture and Forestry P. R.China 1978).

\section{<Table 1 here>}

\section{Estimation of forest net carbon storage}

\section{Carbon in trees}

Trees were sampled in $5 \mathrm{~cm}$ diameter classes, starting at $5 \mathrm{~cm}$ up to the maximum diameter found in the area. If possible, at least three trees in each diameter class were sampled. A total of 2,633 trees were harvested for biomass determination, with equal proportion for all diameter classes. The number of trees cut by species was: 633 Picea asperata, 632 Abies fabri, 334 Pinus koraiensis, 306 Acer mono Maxim., 268 Betula costata, 36 Fraxinus mandshurica Rupr., 378 Tilia amurensis, and 46 trees of other tree species (Table 2). Harvested trees were cut at ground line and dissected into their component parts (trunk, bark, branches, and leaves) to measure fresh weight. Then sectional samples of trunk and bark 
were taken. Disks per stem were selected along the stem every $2 \mathrm{~m}$. The fresh and dry mass of the disks were measured and the fresh mass of the remaining stem sections was measured. The average ratio of dry mass to fresh mass of the disks from either end of the stem section was used to estimate the dry mass of the stem section. Stem mass was the sum of the stem disks plus the sum of the stem section masses (Cordero \& Kanninen 2003; Albaugh et al. 2009). The crown was divided into seven strata to investigate the biomass of branches and leaves. For each stratum, one representative live branch was selected to measure fresh mass of the branch and dry mass of the branch wood and leaf material. The fresh mass of the remaining alive branches in each stratum was recorded. Once the dry masses for leaf and branch wood from the representative branches were measured, the dry mass for the entire stratum could be estimated from the dry mass to fresh mass ratio of the dried branch. Branch and leaf dry mass estimates for all strata were summed for a whole tree estimate of dry mass for branch wood and leaves (Albaugh et al. 2009).

\section{<Table 2 here>}

The most representative biomass allometric models, such as $W=\mathrm{a} D^{\mathrm{b}}, W=\mathrm{a} D^{\mathrm{b}} H^{\mathrm{c}}, W=\mathrm{a}+\mathrm{b} D^{\mathrm{c}}$, and $W=\mathrm{a}+\mathrm{b} D^{2} H$, were tested for best fit of the relationships between individual tree biomass and dimensional parameters, (diameter at breast height $(D)$, total height $(H)$ and diameter at breast height $\times$ height $(D H)) . W$ is the dry weight of a component (trunk, bark, branches and leaves) and $a, b$ and $c$ are scaling factors. For those trees where direct measures were not completed, tree height curve equation s (Table 1) were utilized to predict height from diameter at breast height for the initial and final inventories. The criteria of the model's biological logic and highest adjusted coefficient of determination $\left(R^{2}\right)$ were the basis for choosing the best models for each aboveground biomass component of the canopy layer (Blanco et al. 2007). Then, the Chi-square test was carried out for the regression of the 
different components. Belowground biomass is closely correlated with aboveground biomass for allometric reasons (Kurz et al. 1996; Ruiz-Peinado et al. 2012). Therefore, belowground biomass was determined using 0.23 as the root/shoot biomass ratio, the value reported for spruce-fir mixed forest in Changbai Mountain (Wang et al. 2008).

\section{Carbon in understory}

Understory biomass was estimated in five quadrats of $5 \times 5 \mathrm{~m}$ in each sub-plot used for tree sampling (one in each corner of the sub-plot and one in the center) for 17-18 subplots in each selection cutting intensity in the initial and final inventories (70 understory subplots in total). In each quadrat, aboveground parts of all shrubs and herbs (including ferns and grasses) were cut at the soil surface and weighed separately in the field, and then roots were excavated and weighed after being washed clean (Horwitz 1980). All samples were dried at $85^{\circ} \mathrm{C}$ at the laboratory until they reached a constant weight and were weighed using precision scales to $0.001 \mathrm{~g}$.

\section{Carbon in forest floor}

Forest floor materials (litter) were sampled by establishing five quadrats $1 \times 1 \mathrm{~m}$ in 17-18 soil subplots per cutting intensity (70 soil subplots in total) in the initial and final inventories, air dried, and weighed. Sampling was carried out separately for an upper layer of relatively un-decomposed materials (L layer), and a lower layer of fragmented or decomposed materials (F and $\mathrm{H}$ layers). Subsamples were oven-dried to constant weight to determine air-to-oven dry biomass ratios (Horwitz 1980). Organic biomasses (aboveground, belowground and forest soil) were transformed into organic $\mathrm{C}$ by using $50 \%$ as the average carbon content (Ramirez 2000; Fang et al. 2001; Hikmat 2005). 


\section{Total ecosystem carbon}

Stand level biomass may be estimated directly from individual tree level measurements (Wirth et al. 2004). Aboveground biomass per hectare was calculated using the allometric models developed in this study. Soil C carbon was not monitored as it was beyond the scope of this study and the budget and manpower constrains. Therefore, we assumed that due to the long average remaining times of coarse woody debris and humus in semi-boreal soils, total soil $\mathrm{C}$ was constant during the duration of this study. The forest net $\mathrm{C}$ storage from forest per hectare was then calculated during the monitoring years as follows:

-Aboveground Biomass Stored in the Tree Layer (ABSTL): biomass stored in trunks, barks, branches, leaves.

-Underground Biomass Stored in the Tree Layer (UBSTL): biomass stored in roots.

-Total Biomass Stored in the Tree Layer (TBSTL): ABSTL+UBSTL

-Total Biomass Stored in Shrub, Herb and Litter Layers (TBSSHLL): biomass stored in aboveground and belowground biomass of the shrub, herb and litter layers.

-Total Biomass Stored (TBS): TBSTL+TBSSHLL

-Net Biomass Stored (NBS): Total Biomass Stored of the Final Inventory $\left(\mathrm{TBS}_{\mathrm{FI}}\right)$-Total Biomass Stored of the Initial Inventory $\left(\mathrm{TBS}_{\mathrm{II}}\right)$

-Net Carbon Stored (NCS): NBS $\times 0.5$

\section{Results}

\section{Effects of cutting intensities on stand growth}

There were no significant differences between the 5\% and $10 \%$ cutting intensities during the monitoring years in the annual increments of diameter, basal area and volume of the plots $\left(t_{D B H}=1.914, P_{D B H}\right.$

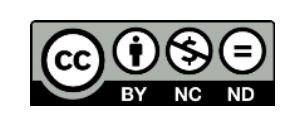


$\left.=0.062 ; t_{B A}=1.358, P_{B A}=0.091 ; t_{V}=1.030, P_{V}=0.121\right)$. Therefore, all the 5 and $10 \%$ plots were grouped together to increase the number of samples for statistical analysis.

The stands with different cutting intensities showed very similar temporal trends for average diameter, basal area, and volume (Table 3). In the period from 1987 to 2006 the annual increments in the managed plots generally exceeded those in the $0 \%$ plots. Annual increments of all tree dimensional variables had significant differences between cutting intensities already after the first inventory period, and these differences increased after 19 years (Table 4). Differences in diameter among cutting intensities were small in the initial inventory (a maximum of $0.9 \mathrm{~cm}$ ), but increased up to $2.3 \mathrm{~cm}$ in the final inventory. Differences between 0\% plots and harvested plots increased as cutting intensity increased (Table 3 and 4).

$<$ Table 3 here > <Table 4 here>

With an increase in cutting intensity, the basal area growth rate also gradually increased. Annual basal area increment in the plots with $20 \%$ basal area removal was $0.85 \pm 0.05 \mathrm{~m}^{2} \mathrm{ha}^{-1} \mathrm{year}^{-1}$ during the 19 years of monitoring, significantly higher than the other plots (Table 4). Total basal area average growth in the plots with $20 \%$ basal area removal was $7.8 \mathrm{~m}^{2} \mathrm{ha}^{-1}$ after 19 years, the biggest among all treatments. The increase in basal area was translated into an increase in volume growth rate, bigger as the cutting intensity progressively increased. Volume in the plots with no area basal removed (0\%) in the final inventory was the lowest in all treatments at $\left(203.4 \pm 8.2 \mathrm{~m}^{3} \mathrm{ha}^{-1}\right.$, Table 3). Annual volume increment in the plots with $20 \%$ basal area removal was $8.04 \pm 0.33 \mathrm{~m}^{3} \mathrm{ha}^{-1} \mathrm{year}^{-1}$, the biggest among all treatments (Table 4). 


\section{Effects of cutting intensities on stand structure}

\section{Changes in diameter distribution}

The diameter distribution of all plots showed a roughly inverse J-shaped curve in the initial inventory, which is the typical diameter distribution of an uneven age mixed forest (Figure 2). However, there was a significant change in diameter distribution after the whole study period, and all plots displayed a left-skewed unimodal curve in the final inventory (Wilcoxon tests, $P=0.011$ to 0.042 ). Much of this variation resulted from the large difference in the relative abundance of the $6 \mathrm{~cm}$ diameter class, which decreased considerably from the average $22.9 \%$ among plots in 1987 to $8.4 \%$ in 2006 . The relative abundance of very large trees ( $\geq 50 \mathrm{~cm}$ DBH) increased from only $0.6 \%$ in 1987 to $1.5 \%$ in 2006 . Moreover, the distribution of diameter class $>10 \mathrm{~cm}$ showed an inverse J-shaped diameter class distribution in the $0 \%$ and managed plots at both the beginning and the end of the research. The difference was that the inverse J-shaped curve leveled off into more horizontal distribution in the final inventory due to a decline in stem density of the smaller trees and a slight increase in the very large trees $(>36 \mathrm{~cm})$.

<Figure 2 here>

Parameters $b$ and $c$ in the diameter Weibull distribution were larger in the final inventory than the initial inventory for all plots (Table 5). Average tree diameter in plots with the higher cutting intensity (15\% and $20 \%$ basal area removal) were significantly different from the plots with the lowest cutting intensity $(0 \%, 5 \%-10 \%$ basal area removal) in the final inventory $(P<0.01)$. The increment in $b$ was only 1.04 in the $0 \%$ plots, but it gradually increased and among the plots with $20 \%$ basal area removal, the average $b$ increment was $4.51 \pm 0.31$, the largest among all treatments. The $c$ value was $<1$ in the initial inventory (Table 5), so the diameter class distribution for all stands showed a roughly inverse J-shaped 
curve (Figure 2). However, the $c$ value was $>1$ in the final inventory (Table 5) and the diameter class distribution showed a similar left-skewed unimodal curve (Figure 2).

$<$ Table 5 here>

\section{Changes in volume ratios among diameter classes}

The diameter class volume ratio of the three $0 \%$ plots did not change between inventories. However, after the two cuttings, there were differences in the diameter class volume ratio in the managed plots (Figure 3). The cutting intensities that removed $5 \%$ and $10 \%$ of the initial basal area were relatively low, so the volume ratio of medium and large diameter classes remained unchanged as the time increased and the volume of large and very large diameter trees accounted for $>50 \%$ in these plots.

<Figure 3 here>

The cutting intensity $15 \%$ produced different results depending on the plots (Figure 3 ). In the I-3 plot, the volume ratio of large and very large trees gradually increased and very large trees accounted for $39.5 \%$ in 2006. In the I-4 plot, the volume ratio of very large trees increased after 1994, but the ratio of large and very large trees, which accounted for $70 \%$ of the stand volume, did not change after 1994. In the II-4 plot, the ratio of large trees did not change significantly after the second cutting but the volume ratio of very large trees increased.

Changes in volume ratio were also plot-dependent for the $20 \%$ treatment. In the I-5 plot, the volume ratio of large and very large diameter classes was always equal or higher than $60 \%$, whereas the volume ratio of the medium diameter class increased to $27.3 \%$ after the second cutting in 1995 , but it had decreased by 2000 . Furthermore, the volume ratio of the very large diameter class always increased in 
the I-5 and II-1 plots. In the II-5 plot, the volume ratio of the small and medium diameter class did not change in the initial and final inventories. After the second cutting, the ratio of the large diameter class was reduced, while for the very large diameter class increased, accounting for $31.9 \%$ in 2006 . The volume ratio of small, medium, large and very large diameter trees was 1:2:3:4 in the I-5 and II-1 plots, but it was 1:3:3:3 in the II-5 plot in the final inventory (Figure 3).

\section{Effects of cutting intensities on forest net carbon storage}

Diameter at breast height $(D)$ and tree height $(H)$ were the best predictor variables for biomass of the different components (Table 6). All the trunk and bark biomass models for the dominant species presented diameter and tree height as independent variables, except for Fraxinus mandshurica, which only contained diameter in bark biomass model. For the branch and leaf biomass models, the diameter was also included in all the models, but the inclusion of tree height was restricted and only for some of the species (Table 6). Goodness-of-fit for all models was moderate to high except for leaf biomass models of Fraxinus mandshurica $(P=0.04)$ and other tree species $(P=0.03)$.

$<$ Table 6 here>

With an increase in cutting intensity, net $\mathrm{C}$ storage of the tree layer gradually increased (Figure 5(A)). The net C storage of the tree layer for $20 \%$ basal area removal was greater than the other intensities reaching more than three times the $0 \%$ plots. The trunk accounted for most of the $\mathrm{C}$ storage in the tree layer (Figure 4(B)). Total forest net C storage was significantly affected by selection cutting intensity treatments (Figure 5(A)), with cutting intensity increasing $\mathrm{C}$ storage compared to plots with $0 \%$ basal area removal. Among all cutting plots, the total net C storage of the plots with $20 \%$ basal area removal was significantly higher, whereas the net $\mathrm{C}$ storage for $0 \%$ plots was the lowest (Table 7). Harvested $\mathrm{C}$ 
and biomass also increased when increasing cutting intensity (Table 8).

$<$ Figure 4 here $\rangle\langle$ Figure 5 here $\rangle\langle$ Table 7 here $\rangle\langle$ Table 8 here $>$

Net biomass and $\mathrm{C}$ storage in each layer followed the order: tree layer> shrub layer> litter layer> herb layer in the plots with $0 \%$ and 5-10\% basal area removal. However, the net biomass and C storage order in the plots with 15 and $20 \%$ basal area removal were different: tree layer> litter layer > shrub layer> herb layer (Figure 5). For all treatments, net biomass and C storage of the tree layer were the most abundant compartment for the whole stand, representing $>94 \%$ of the total net biomass and C storage (Figure 5(A)). Differences in tree layer C storage were not significant among treatments in the initial inventory, but they become significant in the final inventory (Table 7). There were also significant differences in the net $\mathrm{C}$ storage of the herb, shrub and litter layers $(P<0.01)$ between the initial and final inventories for the four different treatments (Table 7). Percentage of net carbon stored in shrubs was affected by the amount of basal area removed, ranging from 1.3 to $2.9 \%$. Net $\mathrm{C}$ stored in the litter layer also changed from 1.3 to $2.6 \%$ of ecosystem net carbon. However, net $\mathrm{C}$ stored in herbs was only slightly affected by cutting intensity, ranging from 0.5 to $0.8 \%$ of net ecosystem C (Table 7).

\section{Discussion}

\section{Selection cutting effects on stand productivity}

This study has analyzed the inventory-based low-intensity selection cutting effects on the forest where this method was firstly introduced into China. It therefore provides the longest monitoring data series on the effects of such management technique on stand attributes. An initial study (1987-1992) in the region was carried out by Yu et al. (1996), although they did not study net C storage. In our results, the annual volume increment after 19 years in the plots with $20 \%$ basal area removal was $8.04 \pm 0.33 \mathrm{~m}^{3} \mathrm{ha}^{-1}$ year ${ }^{-1}$, 
only slightly lower than the one reported by Yu et al. (1996) $\left(8.30 \pm 0.39 \mathrm{~m}^{3} \mathrm{ha}^{-1} \mathrm{year}^{-1}\right)$. Previous studies have reported similar values of annual volume increment $\left(7-8 \mathrm{~m}^{3} \mathrm{ha}^{-1}\right.$ in Couvet village's forests, Switzerland; Cao (1990); $10 \mathrm{~m}^{3} \mathrm{ha}^{-1}$ in Hokkaido, Japan; Yu et al. (1996)), indicating the potential of this technique to sustain high volume growth rates in these forests.

The significant but relatively small increase in average basal area, along with volume, suggested that the forests were still maturing during the study period. Similar results have been found in previous studies (Dai et al. 2011). Low-intensity selection cutting promoted volume growth in all the stands, but there were differences among cutting intensities, with the fastest stand growth rate among the intensities tested being found with $20 \%$ basal area removal. Previous research have reported similar results (Makinen \& Isomaki 2004; Lei et al. 2007). In relative terms, annual volume growth rates for the mixed Manchurian forest $\left(2.10 \pm 0.06 \%\right.$ year $\left.^{-1}\right)$ were also in the same range as reported for mixed forests in Hokkaido (northern Japan) (0.8\%-2.1\% year ${ }^{-1}$, Nigi et al. 1998).

As for the increase in basal area (the predominant stand attribute used by foresters to determine harvest intensity and tree growth), the observed difference of $\left(\sim 0.70 \mathrm{~m}^{2} \mathrm{ha}^{-1} \mathrm{year}^{-1}\right)$ in the plots with $20 \%$ basal area removal compared to the plots with no cuttings was similar to results from other studies (Boncina et al. 2007; Dai et al. 2011). Our results are also similar to the ones from the only other northern mixed forests studied in Asia, in Hokkaido. For this forest type Watanabe (1985a; 1985b) reported 14\% basal area removal as the optimal cutting intensity for timber production when using inventory-based low-intensity selection cutting, whereas a selection cutting regime of $20 \%$ basal area removal every 20 years has been defined as the most sustainable harvesting rate (Yasuda et al. 2013). 


\section{Selection cutting effects on stand structure}

For diameter distribution, our results were similar to that by Yu et al. (1996) in the middle inventory, but the distribution had changed into a left-skewed unimodal curve in the final inventory after 19 years of study. Our results also showed a decrease in small diameter class volume ratio and an increase in very large diameter class, although this increase was less pronounced than that detected in the final inventory. This observation was not consistent with Yu et al.'s (1996) results, who indicated the $20 \%$ cutting intensity promoted tree growth and made the volume structure of diameter classes become more balanced. It seems the changes detected by Yu et al. (1996) were only temporary, as diameter distributions in our research were less affected after the second cutting than after the first one.

A balanced diameter distribution is required to produce a sustainable yield, maintain sustainable development and create the economic, ecological and social benefits, while maintaining a stable stand structure (Leak 1964). This is one of inventory-based low-intensity selection cutting key requirements, which also seeks to maintain a continuous canopy cover in the forest (Schütz et al. 2012). Significant differences between inventories suggested that selection cutting produced clear structural changes in the period from 1987 to 2006. Similar results were found in previous studies (Dai et al. 2011). The decrease in the number of trees for the 6 and $8 \mathrm{~cm}$ diameter classes and the increase in the $>50 \mathrm{~cm}$ diameter class indicated that regeneration was poor and current stand conditions affected the growth of seedlings and saplings, which is consistent with previous observations (Li \& Zhu 1990; Li \& Li 2003). The result of inadequate regeneration of small diameter class trees was attributed to the fact that regenerating seedlings were damaged by forest operations during tending cuttings prior to the plot establishment, as well as during the selection cuttings. In addition, the large experimental setting and the intensive inventorying program required a large and changing staff force that may not have been always properly 
trained in inventorying the small diameter class trees, resulting in the underestimation of the smallest trees. Such problems are inherent to this experiment being the first experience on selection cutting in China, and therefore very few experienced forestry operators, supervisors and scientists could be involved in the experiment. However, there is also room for some natural deviation from the expected inversed J-shape curve. At this uneven-age stands some trees reached ages of 140 years and above, and therefore some patches of the mixed forest could have some old-growth attributes, for which a rotated-sigmoid curve has been described as closer to the equilibrium distribution than the inversed J-shape curve (Lorimer and Frelich 1984, Leak 1996). Therefore, to maintain the inverse J-shaped distribution for a long time, artificial stimulating of natural regeneration would be needed. Alternatively, extending the cutting cycle to 7-8 years may allow for a better recovery of basal area, especially in the treatments with the highest levels of basal area removal (15-20\%).

The increase of $b$ value showed that the diameter of all plots was larger in the final inventory than the initial inventory. The $b$ increment was at a maximum in the $20 \%$ plots, indicating that among the intensities tested, the $20 \%$ basal area removal preferably promoted the growth of trees and increased the volume proportion of large and very large diameter trees, which accounted for $>50 \%$ of stand volume (Figure 3). The $c$ value changed from $<1$ to $>1$ proving the transformation of the curve shape from an inverse J-shape to a left unimodal in all plots (Meng 2006; Merganič \& Sterba 2006).

Significant changes took place in the volume ratio of each diameter class after two cuts in the plots with $20 \%$ basal area removal. The volume ratio of small, medium, large and very large diameters was approximately 1:2:3:4 in the final inventory, which was the optimal diameter class volume ratio of the spruce-fir stand. Our results in the Manchurian mixed forests are different from the ratio reported for the

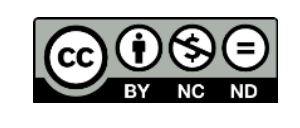


mixed forest in Hokkaido (2.4:3.0:4.6; Kanou 1983). They are also different from the results of Henry Biolley in Switzerland, who suggested that the ideal volume ratio of small, medium and large diameter classes was 2:3:5 (Cao 1990). Our results indicate that the spruce-fir dominated mixed stands in Changbai Mountain were young forest, whereas Biolley carried out a research on a mature forest. The average tree DBH in the Swiss forest studied by Biolley was significantly greater than that of the spruce-fir stand of Changbai Mountain. Therefore, according to the actual conditions of this area it was appropriate that the volume ratio of small, medium, large and very large diameters followed the ratio 1:2:3:4 as a new optimal structural model. However, this diameter class volume ratio is only a temporary index and needs to be improved.

Differently from thinning (which is done mainly to remove the old, weak, sick and malformed trees leaving more growing space for the trees selected for final harvest; Oliver \& Larson 1996), selection cutting removes a mixture of mature (commercial trees) and/or undesirable trees periodically as individuals or in small groups. This technique, integrated with periodic surveys, can be used to maintain a diameter distribution (an inverse J-shaped diameter curve) more similar to natural stands. This is different from traditional thinning, which would gradually level the diameter distribution towards the higher diameter classes. As a consequence, inventory-based selection cutting is better suited for being part of the low-intensity management of the Manchurian mixed forests, as it has been requested to maintain its biodiversity (Yang \& Xu 2003).

\section{Selection cutting effects on C storage}

The highly significant biomass models for different components of the tree layer (except for leaf biomass) indicated the acceptable model behavior when calculating carbon in the tree layer (Blanco et al. 
2007). However, the leaf biomass indicated poor relationships with a relatively low $R^{2}$. These results were also consistent with those observed by Tewfik \& El-Wakeel (2010), who ascribed this phenomenon to the effect of narrow spacing for tree survival. In addition, the ability to predict the biomass of large woody components such as trunks and coarse roots tends to be stronger than that of smaller, shorter lived components such as leaves. Leaf biomass is susceptible to weather, herbivores, and inter-plant competition, among other factors. Meanwhile, it is likely that intraspecific competition influenced crown geometry, and therefore the heterogeneity of leaf biomass from tree to tree (Cole \& Ewel 2006), increasing the difficulty of statistical models such as regressions to estimate accurately leaf biomass (Blanco et al. 2007). Furthermore, when using the mixed model to estimate leaves biomass for the Fraxinus mandshurica and trees for other species pooled together, the allometric equation was not a satisfactory predictor of biomass. This is not surprising as these two groups of trees had an unusually small number of trees sampled, the model only contained diameter at breast height (but not tree height), and the rest of the non-dominant tree species were mixed together for modeling.

The observed net $\mathrm{C}$ storage increase with increase in cutting intensity is likely related to the increase in the gap size created by the selection cuttings. Previous research has found that small gaps are suboptimal for tree growth for both shade-intolerant and shade tolerant species, as they are too dark for the first ones and the competition too strong for the latter ones (Webster and Lorimer 2002). Increasing cutting intensity (and therefore gap size) allows shade-intolerant species to better exploit the productive potential of the site (in terms of nutrients, moisture and crown space) and therefore being more productive. Similarly, for shade-tolerant species, larger gaps can reduce competition and increase productivity. Canopy opening size is also an important determinant of species composition, which can also significantly influence productivity (Phillips and Shure 1990). If the shade-intolerant species 
favored by larger gaps are also fast-growing species, the productivity (and therefore the net $\mathrm{C}$ storage) of the mixed stand increases. Our results agree with previous research on this issue (Webster and Lorimer 2002), although more research may be needed on how productivity of the Manchurian mixed forests reacts to cutting intensities higher than $20 \%$. From previous research in other forest types, it is possible that increased growth rates response to increased gap size would be asymptotic (Canham 1988; Pacala et al. 1994; Duchesneau et al. 2001).

Net increase in biomass and $\mathrm{C}$ storage of the shrub layer were more than the litter layer in the plots with $0 \%$ and $5-10 \%$ basal area removal. However, it was the opposite in the 15 and $20 \%$ selection cutting plots. This is probably because more trees were removed from the sites with high cutting intensity, which left branches, leaves and other coarse woody debris piled on the forest floor, which are then decomposed into large amounts of organic matter, increasing available nutrients when they were mineralized (the "assart effect"; Kimmins 2004). The result was that the site quality had been temporarily improved and further promoted the growth of trees. This effect has been reported before for other tree species in China (Bi et al. 2007; Jie et al. 2011; Blanco et al. 2012; Wang et al. 2013). Our assumption that total soil $\mathrm{C}$ remained stable is based on the fact that the main source of soil $\mathrm{C}$ is coarse woody debris that became humus after decomposition that may last for decades. However if time scales longer than the monitoring period are considered, this assumption may not hold. The observed increase in forest floor layer combined with changes in decomposition rates as the forest floor becomes more exposed to radiation, precipitation and wind. Such exposition may cause increase or decrease of decomposition rates, depending on microsite conditions (Blanco et al. 2010), and therefore is difficult to predict without a proper monitoring program for soil $\mathrm{C}$ changes. 
Total net C storage for each treatment was slightly larger than the one reported by Fang et al. (2001), where the forest net $\mathrm{C}$ storage was derived from timber volume through multiplying the biomass expansion factor using the 50-year national forest resource inventory in China between 1949 and 1998. The relatively low net $\mathrm{C}$ storage in that study compared to our results may be due to several factors: 1 ) The forest $\mathrm{C}$ storage was estimated by Fang et al. (2001) on a national scale, but the estimate in this study was only from Changbai Mountain, using a much more local and accurate forest inventory; 2) The high forest $\mathrm{C}$ storage is strongly linked to the high precipitation and warmer temperature conditions in Changbai Mountain. The average temperature in the forest region of northeast China has increased by $0.066^{\circ} \mathrm{C}_{\text {year }}{ }^{-1}$ over the past two decades (Tan et al. 2007), which could have facilitated the increase in tree growth in the region; 3) Anthropogenic activities such as the large national ecological restoration programs started since the late 1970s (Shen 1999; Tan et al. 2007) may have contributed to variations in $\mathrm{C}$ storage at landscape scale. Meanwhile, the increase in $\mathrm{N}$ deposition from anthropogenic sources that China is experiencing may increase tree growth rates in the latest years compared to earlier periods (Wei et al. 2012).

It is difficult to compare $\mathrm{C}$ storage between sites, even within the same species, because it varies depending on the site index, stocking density and management level of the stands (Satoo \& Madgwick 1982; Balboa-Murias et al. 2006; Wang et al. 2014). Cutting cycles also affect to the potential for C sequestration in uneven-aged systems. Boungiorno et al. (2012) described a 5-year cycle as the most profitable when managed for timber alone, but when $\mathrm{C}$ storage and species diversity were included as management values, lengthening cutting cycles from 5 to 20 years was discussed as a more equilibrated option. We think that in the highly diverse Manchurian mixed forests, also one of the most C-rich in China (Wang et al. 2014), the same pattern could possibly be found, but that question should be studied 
more in detail.

Increasing cutting intensity beyond the $20 \%$ limit may have several consequences in ecosystem structure and function. First, windthrow damage can increase in the remaining trees as they loss protection from neighbouring harvested trees and the gaps could increase in size (Leibundgut 1966; Yu et al. 1996). Second, remaining trees will expand their crowns to occupy the crown space available, therefore reducing their stem growth and generating less merchantable volume. Third, regeneration of shade-intolerant species will be promoted as more light reaches the understory, which could change stand composition over time. Fourth, forest floor decomposition rates may be altered with higher cutting intensities, as increased wind, radiation and direct precipitation would reach forest floor. Depending if the main limiting factor for decomposers at these sites is temperature or moisture, decomposition rates could increase or decrease (Blanco et al. 2011). In any case, soil nutrient availability may be affected and hence tree growth and inter-species competition could also be affected. Giving the complex and non-linear changes that the combination of these factors may have on stand growth, additional research is needed to study the effects of cutting intensities higher than $20 \%$.

\section{Conclusion}

In this study, the long-term effects of inventory-based low-intensity selection cutting on stand growth, structure and net $\mathrm{C}$ storage were examined. When the selection cutting intensity was $20 \%$ basal area removal (the maximum recommended in the control method), the growth rates of average diameter, basal area and volume were relatively high $\left(0.31 \pm 0.01 \mathrm{~cm} \mathrm{year}^{-1}, 0.85 \pm 0.05 \mathrm{~m}^{2} \mathrm{ha}^{-1} \mathrm{year}^{-1}\right.$, and $8.04 \pm 0.33 \mathrm{~m}^{3} \mathrm{ha}^{-1}$ year $^{-1}$, respectively), and the highest among all the selection cutting intensities used. The volume ratio of small, medium, large and very large diameter trees was approximately 1:2:3:4 in 
the final inventory, and the net $\mathrm{C}$ storage from forest was the highest. Therefore, removing $20 \%$ of basal area retained the highest $\mathrm{C}$ storage and improved other structure variables, and therefore it was the best intensity to use within the cutting densities tested.

Our results indicate possibilities for further research to support the implementation of inventory-based low-intensity selection cutting in Changbai Mountain as an alternative and more sustainable forest management. In this study, the time between consecutive cuttings was 5 years. In the future, longer cutting cycles should be set up to compare stand growth, structure change and net $\mathrm{C}$ storage. Moreover, not only stand attributes but other potential effects of selection cutting on ecological process should be explored, such as effects on tree height, biodiversity, natural regeneration, the volume ratio of the coniferous and broad-leaved species, spatial structure, net revenue from wood, population distribution pattern and interspecific association, soil physical and chemical properties, litter nutrient content, or potential genetic divergence in spruce-fir progenies caused by selection cutting. On the other hand, other cutting intensities may be explored, higher than $20 \%$, that although being beyond the low impact forestry that characterizes the control method, they would help to find any potential "optimal" cutting intensity for the stand variables explored here. We hope this study is a first step to promote sustainable forest management through the use of the control method, a close-to-nature continuous-cover forestry system better suited for the management of the multiple values of the Manchurian mixed forests in Changbai Mountain and other sites in Northeast China.

\section{References}

Albaugh TJ, Bergh J, Lundmark T, Nilsson U, Stape JL, Allen HL, Linder S. 2009. Do biological expansion factors adequately estimate stand-scale aboveground component biomass for Norway 
spruce?. For Ecol Manage. 258: 2628-2637.

Angers VA, Messier C, Beaudet M, Leduc A. 2005. Comparing composition and structure in old-growth and harvested (selection and diameter-limit cuts) northern hardwood stands in Quebec. For Ecol Manage. 217: 275-293.

Balboa-Murias MÁ, Rodríguez-Soalleiro R, Merino A, Álvarez-González JG. 2006. Temporal variations and distribution of carbon stocks in aboveground biomass of radiata pine and maritime pine pure stands under different silvicultural alternatives. For Ecol Manage. 237: 29-38.

Benecke U. 1996. Ecological silviculture: the application of age-old methods. N Z Forestry. 41: 27-33.

Bi J, Blanco JA, Seely B, Kimmins JP, Ding Y, Welham C. 2007. Yield decline in Chinese-fir plantations: a simulation investigation with implications for model complexity. Can J For Res. 37: 1615-1630.

Blanco JA, Imbert JB, Castillo FJ. 2011. Thinning affects Pinus sylvestris needle decomposition rates and chemistry differently depending on site conditions. Biogeochem. 106: 397-414.

Blanco JA, Seely B, Welham C, Kimmins JP, Seebacher TM. 2007. Testing the performance of a forest ecosystem model (FORECAST) against 29 years of field data in a Pseudotsuga menziesii plantation. Can J For Res. 37: 1808-1820.

Blanco JA, Wei X, Jiang H, Jie CY, Xin ZH. 2012. Enhanced nitrogen deposition in south-east China could partially offset negative effects of soil acidification on biomass production of Chinese fir plantations. Can J For Res. 42: 437-450.

Bohn KK, Nyland RD, Yanai RD. 2011. Comparing selection system and diameter-limit cutting in uneven-aged northern hardwoods using computer simulation. Can J For Res. 41: 963-973.

Boncina A, Kadunc A, Robic D. 2007. Effects of selective thinning on growth and development of beech (Fagus sylvatica L.) forest stands in south-eastern Slovenia. Ann For Sci. 64: 47-57. 
Boungiorno J, Halvorsen EA, Bollandsas OM, Gobakken T, Hofstad O. 2012. Optimizing management regimes for carbon storage and other benefits in uneven-aged stands dominated by Norway spruce, with a derivation of the economic supply of carbon storage. Scan J For Res 27: 460-473.

Brown AH, Johnson ZB, Chewning JJ, Brown CJ. 1988. Relationships among absolute growth rate, relative growth rate and feed conversion during postweaning feedlot performance tests. J Anim Sci. 66: 2524-2529.

Canham, C.D. 1988. Growth and canopy architecture of shade-tolerant trees: response to canopy gaps. Ecology, 69: 786-795.

Cao X. 1990. Selective cutting. Beijing: China Forestry Press.

Castro-Luna AA, Castillo-Campos G, Sosa VJ. 2011. Effects of selective logging and shifting cultivation on the structure and diversity of a tropical evergreen forest in south-eastern Mexico. $\mathrm{J}$ Trop For Sci. 23: 17-34.

Ciancio O, Iovino F, Menguzzato G, Nicolaci A, Nocentini S. 2006. Structure and growth of a small group selection forest of Calabrian pine in Southern Italy: A hypothesis for continuous cover forestry based on traditional silviculture. For Ecol Manage. 224: 229-234.

Cole TG, Ewel JJ. 2006. Allometric equations for four valuable tropical tree species. For Ecol Manage. 229: $351-360$.

Cordero LDP, Kanninen M. 2003. Aboveground biomass of Tectona grandis plantations in Costa Rica. J Trop For Sci. 15: 199-213.

Dai L, Qi L, Wang Q, Su D, Yu D, Wang Y, Ye Y, Jiang S, Zhao W. 2011. Changes in forest structure and composition on Changbai Mountain in Northeast China. Ann For Sci. 68: 889-897.

Dai L, Zhao F, Shao G, Zhou L, Tang L. 2009. China's Classification-Based Forest Management: Procedures, Problems, and Prospects. Environ Manage. 43: 1162-1173.

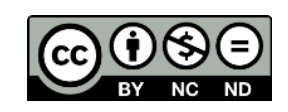


Dannenmann M, Gasche R, Ledebuhr A, Holst T, Mayer H, Papen H. 2007. The effect of forest management on trace gas exchange at the pedosphere-atmosphere interface in beech (Fagus sylvatica L.) forests stocking on calcareous soils. Eur J For Res. 126: 331-346.

Doyon F, Gagnon D, Giroux JF. 2005. Effects of strip and single-tree selection cutting on birds and their habitat in a Southwestern Quebec northern hardwood forest. For Ecol Manage. 209: 101-115.

Duchesneau, R., Lesage, I., Messier, C., and Morin, H. 2001. Effects of light and intraspecific competition on growth and crown morphology of two size classes of understory balsam fir saplings. For. Ecol. Manage. 140: 215-225.

Dyer JH, Gower ST, Forrester JA, Lorimer CG, Mladenoff DJ, Burton JI. 2010. Effects of selective tree harvests on aboveground biomass and net primary productivity of a second-growth northern hardwood forest. Can J For Res. 40: 2360-2369.

Editorial Committee of Jilin Forest. 1988. Jilin Forest. Jilin: Jilin Science and Technology Press.

Falk KJ, Elliott KA, Burke DM, Nol E. 2010. Early seedling response to group selection harvesting in a northern hardwood forest. For Chron. 86: 100-109.

Fang J, Chen A, Peng C, Zhao S, Ci L. 2001. Changes in forest biomass carbon storage in China between 1949 and 1998. Science. 292: 2320-2322.

Forget E, Nolet P, Doyon F, Delagrange S, Jardon Y. 2007. Ten-year response of northern hardwood stands to commercial selection cutting in southern Quebec, Canada. For Ecol Manage. 242: 764-775.

Garber S, Lam TY, Maguire DA. 2011. Growth and Mortality of Residual Douglas-Fir after Regeneration Harvests under Group Selection and Two-Story Silvicultural Systems. West J Appl For. 26: 64-70.

Gronewold CA, D'Amato AW, Palik BJ. 2010. The influence of cutting cycle and stocking level on the 
structure and composition of managed old-growth northern hardwoods. For Ecol Manage. 259: $1151-1160$.

Hao Q, Meng F, Zhou Y, Wang J. 2005. Determining the optimal selective harvest strategy for mixed-species stands with a transition matrix growth model. New For. 29: 207-219.

Heilongjiang's Department of Inventory and Management of Forest Resource. 1971. Forest survey manual. Beijing: China Forestry Press.

Heinrichs S, Schmidt W. 2009. Short-term effects of selection and clear cutting on the shrub and herb layer vegetation during the conversion of even-aged Norway spruce stands into mixed stands. For Ecol Manage. 258: 667-678.

Heiri C, Wolf A, Rohrer L, Bugmann H. 2009. Forty years of natural dynamics in Swiss beech forests: structure, composition, and the influence of former management. Ecol Appl. 19: 1920-1934.

Hikmat A. 2005. Biomass estimation, carbon storage and energy content of three virgin jungle reserves in Peninsular Malaysia. Media Konservasi. 10: 1-8.

Holmes SB, Pitt DG, Mcllwrick KA, Hoepting MK. 2012. Response of bird communities to single-tree selection system harvesting in northern hardwoods: 10-12 years post-harvest. For Ecol Manage. 271: $132-139$.

Horwitz W. 1980. Methods of Analysis. 13th ed. Washington, D.C.: Association of Official Analytical Chemists.

Jalonen J, Vanha-Majamaa I. 2001. Immediate effects of four different felling methods on mature boreal spruce forest understorey vegetation in southern Finland. For Ecol Manage. 146: 25-34.

Jian X, Li X, Liu Y, Shi F. 2006. Selection cutting management technology based on the low-intensity. Beijing: China Forestry Press.

Jie C, Jiang H, Zhou G, Wei X, Blanco J, Jiang Z, Xin Z. 2011. Simulating the carbon storage of spruce 
forests based on the FORECAST model and remotely sensed data. In: Proceedings-2011 19th International Conference on Geoinformatics, Geoinformatics 2011. Article number 5981581.

Kang X. 2011. Forest management. 4th ed. Beijing: China Forestry Press.

Kang X, Hu W, Dong J, Wang D, Li D. 2003. Forest structure dynamics of coniferous-broad leaved mixed forests by management of control method in over-logged forest region. J Beijing For Univ. 25: $1-5$.

Kanou H. 1983. Fundamental Study on the Control Method: Analysis of the Oketo Control Method Experiment Forest belonging to the Hokkaido Prefectural Forest. Bulletin of the Hokkaido Forest Experiment Station. 21: 107-168.

Kató F, Mülder D. 1998. Qualitative Gruppendurchforstung der Buche: Wertentwicklung nach 30 Jahren. Forst und Holz. 53: 131-132, 134-136.

Kimmins JP. 1997. Balancing Act: Environmental Issues in Forestry. 2nd ed. Vancouver, BC: UBC Press.

Kimmins JP. 2004. Forest Ecology: a foundation for sustainable forest management and environmental ethics in forestry. 3rd ed. New Jersey: Prentice Hall.

Kurz WA, Beukema SJ, Apps MJ. 1996. Estimation of root biomass and dynamics for the carbon budget model of the Canadian forest sector. Can J For Res. 26: 1973-1979.

Leak WB. 1964. An Expression of Diameter Distribution for Unbalanced, Uneven-Aged Stands and Forests. Forest Sci. 10: 39-50.

Leak W B. 1996. Long-term structural change in uneven-aged northern hardwoods. For Sci. 42: $160-165$.

Lei X, Lu Y, Peng C, Zhang X, Chang J, Hong L. 2007. Growth and structure development of semi-natural larch-spruce-fir (Larix olgensis-Picea jezoensis-Abies nephrolepis) forests in northeast 
China: 12-year results after thinning. For Ecol Manage. 240: 165-177.

Leibundgut H. 1966. Die Waldpflege. Bern: Haupt Verlag.

Lentner M, Arnold JC, Hinkelmann K. 1989. The efficiency of blocking: how to use MS(Blocks)/MS(Error) correctly. The American Statistician. 43: 106-108.

Li C, Zhou X. 2000. Status and future trends in plantation silviculture in China. J Hum Environ. 29: $354-355$.

Li J, Li J. 2003. Regeneration and restoration of broad-leaved Korean pine forests in Lesser Xing'an Mountains of Northeast China. Acta Ecol Sin. 23: 1268-1277.

Li J, Zhu N. 1990. Population structure of Korean Pine and its dynamics. Chin J Ecol. 9: 6-10.

Liu C, Beaulieu J, Pregent G, Zhang SY. 2009. Applications and comparison of six methods for predicting parameters of the Weibull function in unthinned Picea glauca plantations. Scand J For Res. 24: 67-75.

Lorimer CG, Frelich LE. 1984. A simulation of equilibrium diameter distributions of sugar maple (Acer saccharum). Bull Torr Bot Club. 111: 193-199.

Makinen H, Isomaki A. 2004. Thinning intensity and growth of Norway spruce stands in Finland. Forestry. 77: 349-364.

Meng X. 2006. Forest Measurement. Beijing: China Forestry Press.

Merganič J, Sterba H. 2006. Characterisation of diameter distribution using the Weibull function: method of moments. Eur J For Res. 125: 427-439.

Ministry of Agriculture and Forestry of the People's Republic of China. 1978. Volume table of standing tree. Beijing: [publisher unknown].

Ministry of Forestry of the People's Republic of China. 1996. Contemporary China forest resources situation (1949-1993). Beijing: China Forestry Press. 
Montes F, Sanchez M, del Rio M, Canellas I. 2005. Using historic management records to characterize the effects of management on the structural diversity of forests. For Ecol Manage. 207: 279-293.

Moore TY, Ruel JC, Lapointe MA, Lussier JM. 2012. Evaluating the profitability of selection cuts in irregular boreal forests: an approach based on Monte Carlo simulations. Forestry. 85: 63-77.

Newman JA, Bergelson J, Grafen A. 1997. Blocking factors and hypothesis tests in ecology: is your statistics text wrong?. Ecology. 78: 1312-1320.

Nigi T, Koshika K, Kanuma K, Natsume S, Yone Y, Morita H, Fujito E, Hohjo H. 1998. Managerial progress and results of an experimental forest practiced under the control method, 2: Analysis in Nakagawa Experimental Forest, Hokkaido University. Research Bulletins of the College Experiment Forests-Hokkaido University. 55: 274-308.

Oliver CD, Larson BC. 1996. Forest Stand Dynamics. Update ed. New York: Wiley.

Ontario Ministry of Natural Resources. 2004. Ontario tree marking guide. Version 1.1. Toronto: Ontario Ministry of Natural Resources, Queen's Printer for Ontario. Available from: http://www.mnr.gov.on.ca/stdprodconsume/groups/lr/@mnr/@forests/documents/document/mnr_e0 00526.pdf

Pacala, S.W., Canham, C.D., Silander, J.A., Jr., and Kobe, R.K. 1994. Sapling growth as a function of resources in a northern temperate forest. Can. J. For. Res. 24: 2172-2183.

Phillips, D.L., and Shure, D.J. 1990. Patch-size effects on early succession in southern Appalachian forests. Ecology, 71: 204-212.

Quinn GP, Keough MJ. 2002. Experimental design and data analysis for biologists. Cambridge, UK: Cambridge University Press.

Ramirez OA. 2000. The carbon cycle and the value of forests as a carbon sink: a tropical case study. In: Dore M, Guevara R, editors. Sustainable forest management and global climate change: Selected 
case studies from the Americas. Cheltenham: Edward Elgar Publishing Limited; p. 107-147.

Robertson S, Myketa D. 1998. The selection silvicultural system as related to vegetation management. In: Bell FW, McLaughlan M, Kerley J, editors. Vegetation Management Alternatives - A Guide to Opportunities. Thunder Bay: Ontario Ministry of Natural Resources; p. 1-11.

Ruiz-Peinado R, Montero G, del Rio M. 2012. Biomass models to estimate carbon stocks for hardwood tree species. Forest Syst. 21: 42-52.

SAS I. 1999. SAS/STAT user's guide. 8th ed. North Carolina: SAS Institute Inc.

Satoo T, Madgwick HAI. 1982. Forest Biomass. Dordrecht: Kluwer Academic Publishers Group.

Schütz JP, Pukkala T, Donoso PJ, von Gadow K. 2012. Historical emergence and current application of CCF. In: Pukkala T, von Gadow K, editors. Continuous Cover Forestry, Managing Forest Ecosystems 23. Berlin: Springer; p. 1-28.

Shao G, Zhang P, Bai G, Zhao G, Wang Z. 2001. Ecological classification system for China's natural forests: protection and management. Acta Ecol Sin. 21: 1564-1568.

Shao G, Zhao G. 1998. Protection versus harvest of old-growth forests on Changbai Mountain (China and North Korea): a remote sensing application. Nat Area J. 18: 358-365.

Shao G, Wang H, Dai L, Wu G, Li Y, Lang R, Song B. 2005. Integrating stand and landscape decisions for multi-purposes of forest harvesting. For Ecol Manage. 207: 233-243.

Shen G. 1999. Sustainable Forest Management in China. Guilin: Guangxi Science and Technology Press.

State Forestry Administration of China. 2009. The seventh national forest resource inventory and the status of forest resource. Beijing: China Forestry Press.

Streitberg B, Röhmel J. 1986. Exact distributions for permutation and rank tests: an introduction to some recently published algorithms. Stat Softw Newsl. 12: 10-17.

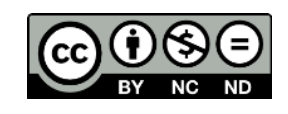


Tan K, Piao S, Peng C, Fang J. 2007. Satellite-based estimation of biomass carbon stocks for northeast China's forests between 1982 and 1999. For Ecol Manage. 240: 114-121.

Tewfik S, El-Wakeel A. 2010. Effect of Thinning on the above Ground Biomass of (Conocarpus erectus L.) Trees in the Western Region of Saudi Arabia. Met, Env \& Arid Land Agric Sci. 21: 3-17.

Wang X, Fang J, Zhu B. 2008. Forest biomass and root-shoot allocation in northeast China. For Ecol Manage. 255: 4007-4020.

Wang D, Wang B, Niu X. 2014. Forest carbon sequestration in China and its benefits. Scan J For Res 29: 51-59.

Wang W, Wei X, Liao W, Blanco JA, Liu Y, Liu S, Liu G, Zhang L, Guo X, Guo S. 2013. Evaluation of the effects of forest management strategies on carbon sequestration in evergreen broad-leaved (Phoebe bournei) plantation forests using FORECAST ecosystem model. For Ecol Manage. 300: 21-32.

Webster C.R., Lorimer C.G. 2002. Single-tree versus group selection in hemlock-hrdwood forests: are smaller openings less productive? Can J For Res. 32: 591-604.

Wei X, Blanco JA, Jiang H, Kimmins JP. 2012. Effects of nitrogen deposition on carbon sequestration in Chinese fir forest ecosystems. Sci Total Environ. 416: 351-361.

Weibull BW, Sweden S. 1951. A statistical distribution function of wide applicability. J Appl Mech. 18: 293-297.

Watanabe S. 1985a. The new expansion of harvesting forestry. Mountain Forests. 1215: 2-21.

Watanabe S. 1985b. Research of forest community for the natural forest in Hokkaido. Hokkaido: Hokkaido regional forestry office.

Wirth C, Schumacher J, Schulze ED. 2004. Generic biomass functions for Norway spruce in Central Europe - a meta-analysis approach toward prediction and uncertainty estimation. Tree Physiol. 24: 
$121-139$.

Wu X, Brueggemann N, Gasche R, Papen H, Willibald G, Butterbach-Bahl K. 2011. Long-term effects of clear-cutting and selective cutting on soil methane fluxes in a temperate spruce forest in southern Germany. Environ Pollut. 159: 2467-2475.

Yang X, Xu M. 2003. Biodiversity conservation in Changbai Mountain Biosphere Reserve, northeastern China: status, problem, and strategy. Biodivers Conserv. 12: 883-903.

Yasuda A, Yoshida T, Miya H, Harvey BD. 2013. An alternative management regime of selection cutting for sustaining stand structure of mixed forests of northern Japan: a simulation study. J For Res. 18: 398-406.

Yu Z. 1995. Quantitative forest management. Beijing: China Forestry Press.

Yu Z, Kang X, Li F, Zhou Y, Li D. 1996. A primary study on the technic of control method. Sci Silv Sin. 32: $24-34$.

Zhao F, Yang J, Liu Z, Dai L, He HS. 2011. Balancing Multiple Objectives Using a Classification-Based Forest Management System in Changbai Mountains, China. Environ Manage. 48: 1136-1147.

Zhao G, Shao G. 2002. Logging restrictions in China: a turning point for forest sustainability. J For. 100: 34-37. 
Table 1. Equations used to estimate height and volume for the main tree species in Changbai Mountain.

\begin{tabular}{lll}
\hline Tree height & Volume & Tree species \\
\hline$H=46.4026-2137.9188(D+47.0)^{-1}$ & $V=0.000057862 D^{1.88920} H^{0.98755}$ & Spruce, Fir, Korean pine \\
$H=29.4425-468.9247(D+15.7)^{-1}$ & $V=0.000053309 D^{1.88452} H^{0.99834}$ & Maple, Linden, \\
& & Manchurian ash, Elm \\
$H=24.8174-402.0877(D+16.3)^{-1}$ & $V=0.000048841 D^{1.84048} H^{1.05252}$ & Acer mono and other tree \\
& & species \\
\hline
\end{tabular}


Table 2. Minimum, maximum and mean values of diameter and height for the sample trees of the studied species used to test estimated biomass equations. S.D.: standard deviation.

\begin{tabular}{lccccc}
\hline \multirow{2}{*}{ Species } & \multirow{2}{*}{$\begin{array}{c}\text { Number } \\
\text { of trees }\end{array}$} & \multicolumn{2}{c}{ Diameter at breast height (cm) } & \multicolumn{2}{c}{ Height(m) } \\
\cline { 3 - 6 } & & Mean/ S.D. & Min/Max & Mean/ S.D. & Min/Max \\
\hline Picea asperata & 633 & $18.4 / 0.4$ & $5.9 / 55.9$ & $13.0 / 0.2$ & $4.4 / 29.2$ \\
Abies fabri & 632 & $20.0 / 0.4$ & $6.0 / 51.3$ & $14.7 / 0.2$ & $5.0 / 26.2$ \\
Pinus koraiensis & 334 & $20.9 / 0.6$ & $5.8 / 49.2$ & $13.1 / 0.2$ & $4.8 / 26.2$ \\
Acer mono & 306 & $16.2 / 0.4$ & $5.8 / 40.3$ & $11.8 / 0.1$ & $6.0 / 20.2$ \\
Betula costata & 268 & $14.2 / 0.5$ & $5.8 / 57.3$ & $14.0 / 0.2$ & $6.5 / 25.2$ \\
Fraxinus mandshurica & 36 & $14.4 / 1.3$ & $5.9 / 38.5$ & $14.3 / 0.5$ & $8.3 / 20.8$ \\
Tilia amurensis & 378 & $14.5 / 0.4$ & $6.0 / 49.7$ & $11.4 / 0.1$ & $5.9 / 21.9$ \\
Others & 46 & $15.5 / 1.1$ & $6.1 / 47.0$ & $14.4 / 0.5$ & $8.2 / 20.8$ \\
\hline
\end{tabular}


Table 3. Mean ( \pm standard error) diameter, basal area, and volume for different selection cutting intensities for the three inventories. Superindex letters in the same row indicate significant differences between treatments (Tukey HSD, $p<0.05$ ).

\begin{tabular}{lcccccc}
\hline Basal area removal & $\mathbf{0 \%}$ & $\mathbf{5 - 1 0 \%}$ & $\mathbf{1 5 \%}$ & $\mathbf{2 0 \%}$ & $\boldsymbol{F}$ & $\boldsymbol{p}$ \\
\hline Number of plots & 3 & 4 & 3 & 3 & - & - \\
DBH (cm) & & & & & & \\
Initial inventory (1987) & $13.1 \pm 0.3^{\mathrm{a}}$ & $13.6 \pm 0.1^{\mathrm{ab}}$ & $13.0 \pm 0.3^{\mathrm{a}}$ & $12.7 \pm 0.3^{\mathrm{ac}}$ & 2.075 & 0.174 \\
Middle inventory (1996) & $14.3 \pm 0.2^{\mathrm{a}}$ & $15.5 \pm 0.2^{\mathrm{a}}$ & $15.5 \pm 0.6^{\mathrm{a}}$ & $15.3 \pm 0.5^{\mathrm{a}}$ & 1.927 & 0.196 \\
Final inventory (2006) & $15.6 \pm 0.2^{\mathrm{a}}$ & $17.5 \pm 0.3^{\mathrm{b}}$ & $17.9 \pm 0.2^{\mathrm{b}}$ & $17.8 \pm 0.3^{\mathrm{b}}$ & 13.154 & 0.001 \\
Basal area (m $\left.\mathbf{m}^{2}\right)$ & & & & & & \\
Initial inventory (1987) & $21.2 \pm 1.3^{\mathrm{a}}$ & $23.1 \pm 0.4^{\mathrm{ab}}$ & $20.6 \pm 0.4^{\mathrm{ac}^{\mathrm{c}}}$ & $20.3 \pm 0.8^{\mathrm{ac}}$ & 2.937 & 0.092 \\
Middle inventory (1996) & $22.9 \pm 1.5^{\mathrm{a}}$ & $25.0 \pm 0.5^{\mathrm{a}}$ & $22.1 \pm 0.5^{\mathrm{a}}$ & $22.6 \pm 2.2^{\mathrm{a}}$ & 1.143 & 0.383 \\
Final inventory (2006) & $24.1 \pm 1.8^{\mathrm{a}}$ & $27.1 \pm 0.3^{\mathrm{a}}$ & $26.5 \pm 0.2^{\mathrm{a}}$ & $28.1 \pm 1.1^{\mathrm{b}}$ & 4.009 & 0.049 \\
Volume (m $\left.\mathbf{3}^{3}\right)$ & & & & & & \\
Initial inventory (1987) & $176.2 \pm 8.0^{\mathrm{a}}$ & $190.1 \pm 3.2^{\mathrm{ab}}$ & $174.6 \pm 4.1^{\mathrm{a}}$ & $167.5 \pm 7.8^{\mathrm{ac}}$ & 2.973 & 0.089 \\
Middle inventory (1996) & $188.7 \pm 7.6^{\mathrm{a}}$ & $213.4 \pm 5.9^{\mathrm{a}}$ & $194.5 \pm 11.1^{\mathrm{a}}$ & $196.2 \pm 20.4^{\mathrm{a}}$ & 0.919 & 0.470 \\
Final inventory (2006) & $203.4 \pm 8.2^{\mathrm{a}}$ & $242.6 \pm 5.6^{\mathrm{b}}$ & $245.2 \pm 8.0^{\mathrm{b}}$ & $242.3 \pm 8.0^{\mathrm{b}}$ & 7.181 & 0.009 \\
\hline
\end{tabular}


Table 4. Annual increments (mean \pm standard error) of stand attributes for different selection cutting intensities monitored the first half of the study period (1987-1996), and the total study period (1987-2006). Superindex letters in the same row indicate significant differences between groups (Tukey HSD $p<0.05$ ).

\begin{tabular}{|c|c|c|c|c|c|c|}
\hline Basal area removal & $0 \%$ & $5-10 \%$ & $15 \%$ & $20 \%$ & $\boldsymbol{F}$ & $p$ \\
\hline Number of plots & 3 & 4 & 3 & 3 & - & - \\
\hline \multicolumn{7}{|l|}{ First half (1987-1996) } \\
\hline Diameter rate $\left(\mathrm{cm}\right.$ year $\left.^{-1}\right)$ & $0.13 \pm 0.02^{\mathrm{a}}$ & $0.28 \pm 0.06^{\mathrm{b}}$ & $0.33 \pm 0.02^{\mathrm{c}}$ & $0.33 \pm 0.02^{\mathrm{c}}$ & 4.244 & 0.040 \\
\hline Basal area rate $\left(\mathrm{m}^{2} \mathrm{ha}^{-1} \mathrm{year}^{-1}\right)$ & $0.17 \pm 0.03^{\mathrm{a}}$ & $0.57 \pm 0.08^{\mathrm{b}}$ & $0.83 \pm 0.07^{\mathrm{bc}}$ & $1.13 \pm 0.20^{\mathrm{c}}$ & 12.316 & 0.002 \\
\hline Volume rate $\left(\mathrm{m}^{3} \mathrm{ha}^{-1}\right.$ year $\left.{ }^{-1}\right)$ & $1.35 \pm 0.14^{\mathrm{a}}$ & $5.46 \pm 0.92^{\mathrm{ab}}$ & $7.73 \pm 0.95^{\mathrm{b}}$ & $10.35 \pm 1.96^{\mathrm{b}}$ & 10.152 & 0.003 \\
\hline \multicolumn{7}{|l|}{ Total study (1987-2006) } \\
\hline Diameter rate $\left(\mathrm{cm}\right.$ year $\left.{ }^{-1}\right)$ & $0.13 \pm 0.01^{\mathrm{a}}$ & $0.29 \pm 0.05^{\mathrm{b}}$ & $0.28 \pm 0.04^{\mathrm{c}}$ & $0.31 \pm 0.01^{\mathrm{c}}$ & 4.950 & 0.027 \\
\hline Basal area rate $\left(\mathrm{m}^{2} \mathrm{ha}^{-1} \mathrm{year}^{-1}\right)$ & $0.16 \pm 0.03^{\mathrm{a}}$ & $0.46 \pm 0.06^{\mathrm{b}}$ & $0.66 \pm 0.02^{\mathrm{c}}$ & $0.85 \pm 0.05^{\mathrm{d}}$ & 39.304 & $<0.001$ \\
\hline Volume rate $\left(\mathrm{m}^{3} \mathrm{ha}^{-1}\right.$ year $\left.^{-1}\right)$ & $1.51 \pm 0.07^{\mathrm{a}}$ & $4.38 \pm 0.61^{\mathrm{b}}$ & $6.70 \pm 0.10^{\mathrm{c}}$ & $8.04 \pm 0.33^{\mathrm{c}}$ & 43.327 & $<0.001$ \\
\hline
\end{tabular}


Table 5. Values (mean \pm standard error) of parameters $b$ and $c$ for the Weibull distribution of stem diameters in the initial and final inventories under different selection cutting intensities. Different superindex letters in the same row represent a significant difference (Tukey HSD, $p$ $<0.05)$.

\begin{tabular}{lcccccc}
\hline Basal area removal & $\mathbf{0 \%}$ & $\mathbf{5 - 1 0 \%}$ & $\mathbf{1 5 \%}$ & $\mathbf{2 0 \%}$ & $\boldsymbol{F}$ & $\boldsymbol{p}$ \\
\hline Number of plots & 3 & 4 & 3 & 3 & - & - \\
Initial $b$ & $9.26 \pm 0.27^{\mathrm{a}}$ & $8.53 \pm 0.38^{\mathrm{a}}$ & $9.09 \pm 0.61^{\mathrm{a}}$ & $8.25 \pm 0.30^{\mathrm{a}}$ & 1.260 & 0.345 \\
Final $b$ & $10.30 \pm 0.28^{\mathrm{a}}$ & $10.89 \pm 0.12^{\mathrm{a}}$ & $12.82 \pm 0.58^{\mathrm{b}}$ & $12.76 \pm 0.35^{\mathrm{b}}$ & 13.682 & 0.001 \\
Initial $c$ & $0.94 \pm 0.02^{\mathrm{a}}$ & $0.93 \pm 0.02^{\mathrm{a}}$ & $0.95 \pm 0.01^{\mathrm{a}}$ & $0.94 \pm 0.03^{\mathrm{a}}$ & 0.367 & 0.779 \\
Final $c$ & $1.04 \pm 0.01^{\mathrm{a}}$ & $1.06 \pm 0.03^{\mathrm{a}}$ & $1.10 \pm 0.01^{\mathrm{a}}$ & $1.11 \pm 0.03^{\mathrm{a}}$ & 2.131 & 0.166 \\
\hline
\end{tabular}


Table 6. Biomass models fitted for different components and fitting statistics for the dominant species. $N$ is the number of trees used; $W$ is dry weight of the different tree components $(\mathrm{kg}) ; D$ is diameter at breast height $(\mathrm{cm}) ; H$ is tree height $(\mathrm{m}) ; R^{2}$ is coefficient of determination and $p$ values indicate the goodness-of-fit of the model to the field data (higher $p$ indicates better fit).

\begin{tabular}{|c|c|c|c|c|}
\hline Species & Components & Biomass models & $R^{2}$ & $p$ \\
\hline Picea asperata & Trunk & $W=0.013 D^{1.897} H^{1.134}$ & 0.92 & 0.82 \\
\hline \multirow[t]{3}{*}{$N=633$} & Bark & $W=0.020 D^{2.308} H^{(-0.165)}$ & 0.84 & 0.64 \\
\hline & Branch & $W=0.028 D^{2.047}$ & 0.88 & 0.50 \\
\hline & Leaf & $W=0.172 D^{1.567}$ & 0.68 & 0.23 \\
\hline Abies fabri & Trunk & $W=0.038 D^{1.487} H^{1.258}$ & 0.96 & 0.90 \\
\hline \multirow[t]{3}{*}{$N=632$} & Bark & $W=0.001 D^{2.015} H^{1.348}$ & 0.87 & 0.70 \\
\hline & Branch & $W=0.008 D^{2.548} H^{(-0.283)}$ & 0.83 & 0.44 \\
\hline & Leaf & $W=0.006 D^{2.558} H^{(-0.223)}$ & 0.64 & 0.31 \\
\hline Pinus koraiensis & Trunk & $W=0.020 D^{1.841} H^{1.109}$ & 0.90 & 0.74 \\
\hline \multirow[t]{3}{*}{$N=334$} & Bark & $W=0.010 D^{2.059} H^{0.239}$ & 0.82 & 0.59 \\
\hline & Branch & $W=0.0003 D^{3.818} H^{(-0.711)}$ & 0.87 & 0.41 \\
\hline & Leaf & $W=0.002 D^{2.909} H^{(-0.467)}$ & 0.55 & 0.19 \\
\hline Acer mono & Trunk & $W=0.025 D^{1.792} H^{1.155}$ & 0.96 & 0.72 \\
\hline \multirow[t]{3}{*}{$N=306$} & Bark & $W=0.005 D^{1.541} H^{1.383}$ & 0.78 & 0.49 \\
\hline & Branch & $W=-32.200+4.395 D^{2}$ & 0.77 & 0.33 \\
\hline & Leaf & $W=-6.316+0.253 D^{2} H$ & 0.57 & 0.17 \\
\hline Betula costata & Trunk & $W=0.018 D^{1.696} H^{1.387}$ & 0.87 & 0.64 \\
\hline \multirow[t]{3}{*}{$N=268$} & Bark & $W=1.232+0.003 D^{2} H$ & 0.88 & 0.49 \\
\hline & Branch & $W=-4.168+0.070 D^{2}$ & 0.72 & 0.28 \\
\hline & Leaf & $W=-0.626+0.010 D^{2}$ & 0.62 & 0.25 \\
\hline $\begin{array}{l}\text { Fraxinus } \\
\text { mandshurica }\end{array}$ & Trunk & $W=0.092 D^{1.909} H^{0.543}$ & 0.81 & 0.52 \\
\hline \multirow[t]{3}{*}{$N=36$} & Bark & $W=-6.454+1.281 \mathrm{D}$ & 0.77 & 0.40 \\
\hline & Branch & $W=-22.249+2.745 D$ & 0.72 & 0.29 \\
\hline & Leaf & $W=-2.789+0.344 D$ & 0.42 & 0.04 \\
\hline \multirow{4}{*}{$\begin{array}{l}\text { Tilia amurensis } \\
N=378\end{array}$} & Trunk & $W=0.038 D^{1.969} H^{0.687}$ & 0.96 & 0.77 \\
\hline & Bark & $W=0.011 D^{1.075} H^{1.606}$ & 0.76 & 0.55 \\
\hline & Branch & $W=0.0005 D^{3.308} H^{0.181}$ & 0.94 & 0.46 \\
\hline & Leaf & $W=0.001 D^{3.308} H^{0.181}$ & 0.59 & 0.26 \\
\hline \multirow{4}{*}{$\begin{array}{l}\text { Other tree } \\
\text { species } \\
N=46\end{array}$} & Trunk & $W=0.026 D^{1.761} H^{1.112}$ & 0.80 & 0.49 \\
\hline & Bark & $W=0.781+0.002 D^{2} H$ & 0.76 & 0.15 \\
\hline & Branch & $W=-6.536+1.151 \mathrm{D}$ & 0.74 & 0.29 \\
\hline & Leaf & $W=-2.433+0.409 D$ & 0.51 & 0.03 \\
\hline
\end{tabular}


Y. Liu et al. (2014) Scandinavian Journal of Forest Research, 29(5):436-454 46/49

Table 7. ANOVA of net carbon storage $\left(\mathrm{Mg} \mathrm{ha}^{-1}\right)$ in the total forest and different components (mean \pm standard error) based on different selection cutting intensity plots in the 1987-2006 period. Superindex letters in the same column represent significant differences (Tukey HSD, $p<0.05)$.

\begin{tabular}{lcccccccc}
\hline \multirow{2}{*}{$\begin{array}{l}\text { Basal } \\
\text { area }\end{array}$} & $n$ & \multicolumn{2}{c}{ Tree layer carbon storage } & \multicolumn{3}{c}{ Net carbon increase in 19 years } & \multirow{2}{*}{ Total } \\
\cline { 2 - 7 } removal & & Initial (1987) & Final (2006) & Tree & Shrub & Herb & Litter & \\
\hline $0 \%$ & 3 & $56.51 \pm 0.87^{\mathrm{a}}$ & $63.36 \pm 0.72^{\mathrm{a}}$ & $6.86 \pm 0.18^{\mathrm{a}}$ & $0.17 \pm 0.02^{\mathrm{a}}$ & $0.05 \pm 0.01^{\mathrm{a}}$ & $0.14 \pm 0.01^{\mathrm{a}}$ & $7.21 \pm 0.17^{\mathrm{a}}$ \\
$5-10 \%$ & 4 & $56.78 \pm 0.54^{\mathrm{a}}$ & $67.96 \pm 0.47^{\mathrm{ab}}$ & $11.19 \pm 0.88^{\mathrm{b}}$ & $0.25 \pm 0.01^{\mathrm{b}}$ & $0.08 \pm 0.00^{\mathrm{b}}$ & $0.18 \pm 0.02^{\mathrm{ab}}$ & $11.68 \pm 0.91^{\mathrm{b}}$ \\
$15 \%$ & 3 & $54.96 \pm 1.62^{\mathrm{a}}$ & $75.65 \pm 1.62^{\mathrm{c}}$ & $20.69 \pm 0.26^{\mathrm{c}}$ & $0.29 \pm 0.00^{\mathrm{c}}$ & $0.11 \pm 0.00^{\mathrm{c}}$ & $0.33 \pm 0.02^{\mathrm{c}}$ & $21.41 \pm 0.28^{\mathrm{c}}$ \\
$20 \%$ & 3 & $54.51 \pm 1.91^{\mathrm{a}}$ & $79.73 \pm 2.80^{\mathrm{c}}$ & $25.23 \pm 1.16^{\mathrm{d}}$ & $0.46 \pm 0.01^{\mathrm{d}}$ & $0.13 \pm 0.00^{\mathrm{d}}$ & $0.66 \pm 0.01^{\mathrm{d}}$ & $26.47 \pm 1.18^{\mathrm{d}}$ \\
$F$ & & 0.820 & 21.999 & 111.216 & 110.726 & 87.311 & 177.976 & 114.690 \\
$p$ & 0.515 & $<0.001$ & $<0.001$ & $<0.001$ & $<0.001$ & $<0.001$ & $<0.001$ \\
\hline
\end{tabular}


Table 8. ANOVA of tree biomass and carbon removed $\left(\mathrm{Mg} \mathrm{ha}^{-1}\right.$, mean \pm standard error $)$ for different selection cutting intensities 1987-2006 period. Superindex letters in the same column represent significant differences (Tukey HSD, $p<0.05$ ).

\begin{tabular}{|c|c|c|c|c|c|c|c|}
\hline \multirow{2}{*}{$\begin{array}{l}\text { Basal } \\
\text { area } \\
\text { removal }\end{array}$} & \multirow[t]{2}{*}{$n$} & \multicolumn{5}{|c|}{ Accumulated biomass } & \multirow{2}{*}{$\begin{array}{c}\text { Accumulated C } \\
\text { removed }\end{array}$} \\
\hline & & Trunk & Bark & Branch & Leaf & Aboveground & \\
\hline $0 \%$ & 3 & $0.00 \pm 0.00^{\mathrm{a}}$ & $0.00 \pm 0.00^{\mathrm{a}}$ & $0.00 \pm 0.00^{\mathrm{a}}$ & $0.00 \pm 0.00^{\mathrm{a}}$ & $0.00 \pm 0.00^{\mathrm{a}}$ & $0.00 \pm 0.00^{\mathrm{a}}$ \\
\hline $5-10 \%$ & 4 & $7.70 \pm 0.83^{b}$ & $1.44 \pm 0.17^{\mathrm{b}}$ & $0.90 \pm 0.10^{\mathrm{a}}$ & $0.86 \pm 0.24^{\mathrm{ab}}$ & $10.89 \pm 1.01^{\mathrm{b}}$ & $5.45 \pm 0.50^{\mathrm{b}}$ \\
\hline $15 \%$ & 3 & $19.63 \pm 1.09^{\mathrm{c}}$ & $3.34 \pm 0.35^{\mathrm{c}}$ & $2.64 \pm 0.32^{\mathrm{b}}$ & $1.29 \pm 0.36^{\mathrm{bc}}$ & $26.90 \pm 0.98^{\mathrm{c}}$ & $13.45 \pm 0.49^{\mathrm{c}}$ \\
\hline $20 \%$ & 3 & $22.04 \pm 0.80^{\mathrm{c}}$ & $3.73 \pm 0.14^{\mathrm{c}}$ & $3.21 \pm 0.52^{\mathrm{b}}$ & $2.12 \pm 0.12^{\mathrm{c}}$ & $31.10 \pm 0.53^{\mathrm{d}}$ & $15.55 \pm 0.27^{\mathrm{d}}$ \\
\hline$F$ & & 0.820 & 153.716 & 67.362 & 26.241 & 13.548 & 291.190 \\
\hline$p$ & & 0.515 & $<0.001$ & $<0.001$ & $<0.001$ & 0.001 & $<0.001$ \\
\hline
\end{tabular}




\section{Figures}

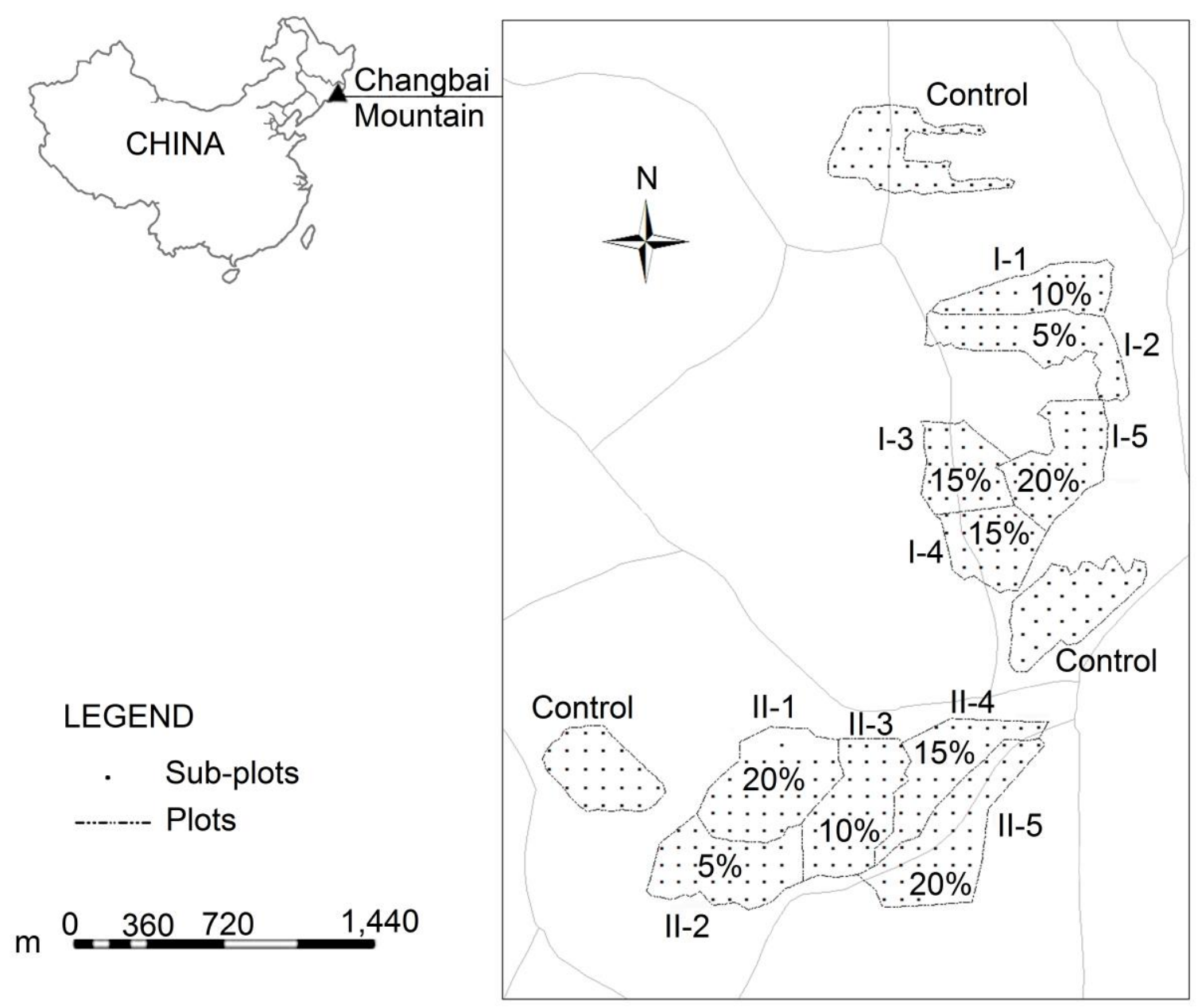

Figure 1. Location of the Blocks I and II, plots (encircled areas), and 274 subplots (dots), used to test the inventory-based low-intensity selection cutting method in Changbai Mountain, Northeastern China. 


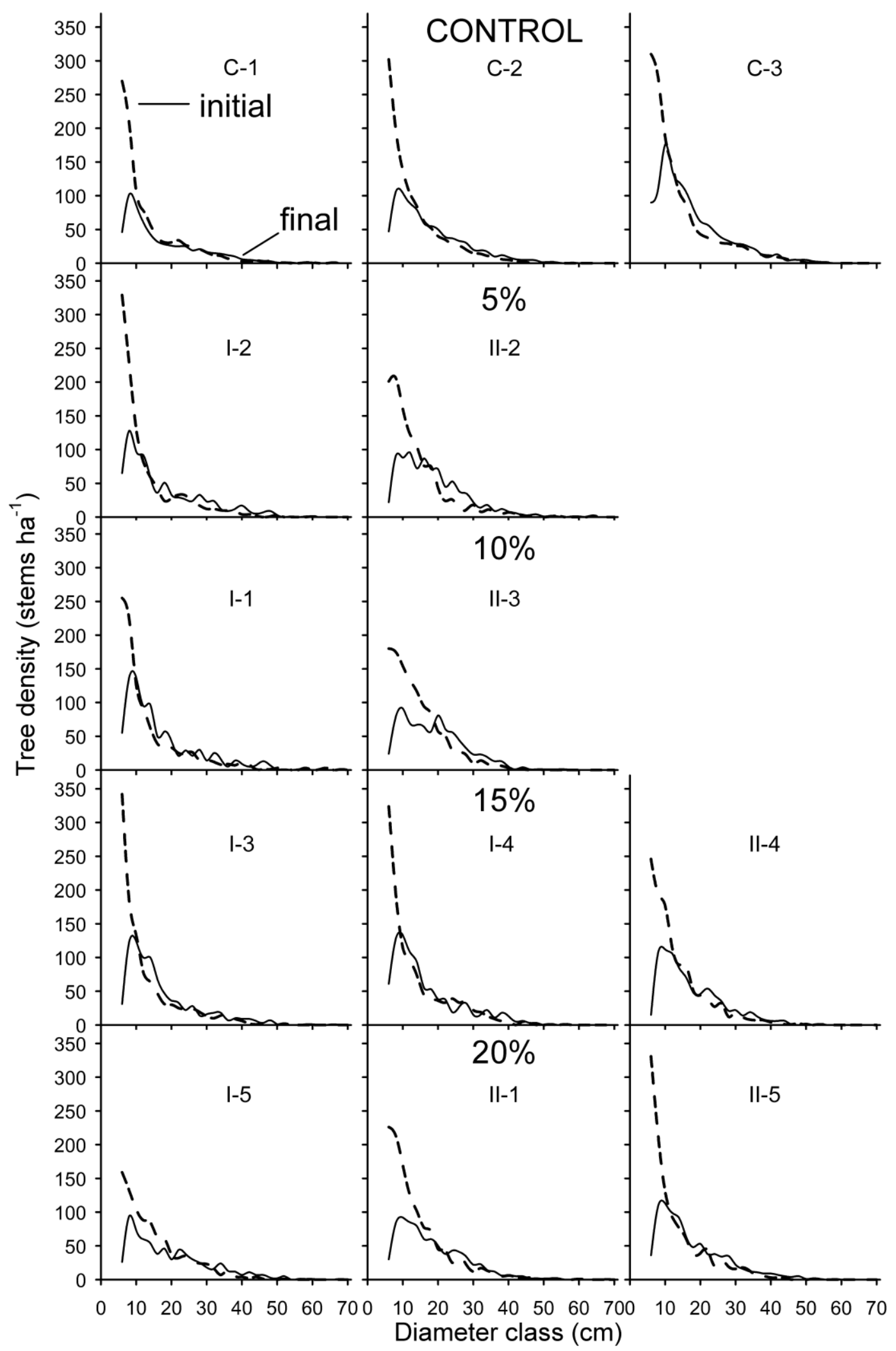

Figure 2. Stand diameter distributions for the different plots in 1987 (initial inventory, dotted line) and 2006 (final inventory, continuous line). 

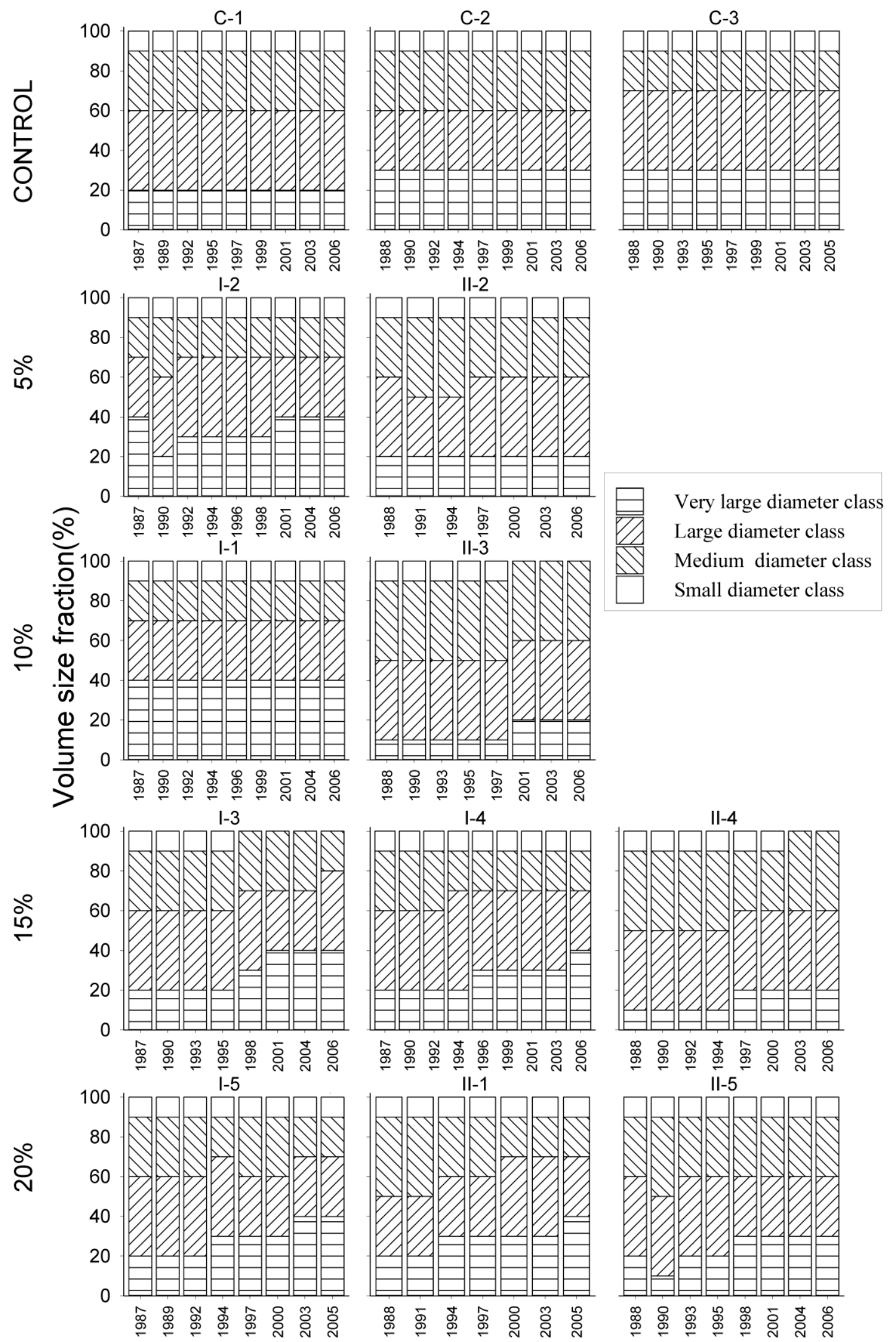

Figure 3. Change in the stand volume ratio for diameter classes under different selection cutting intensities along 19 years of monitoring. 

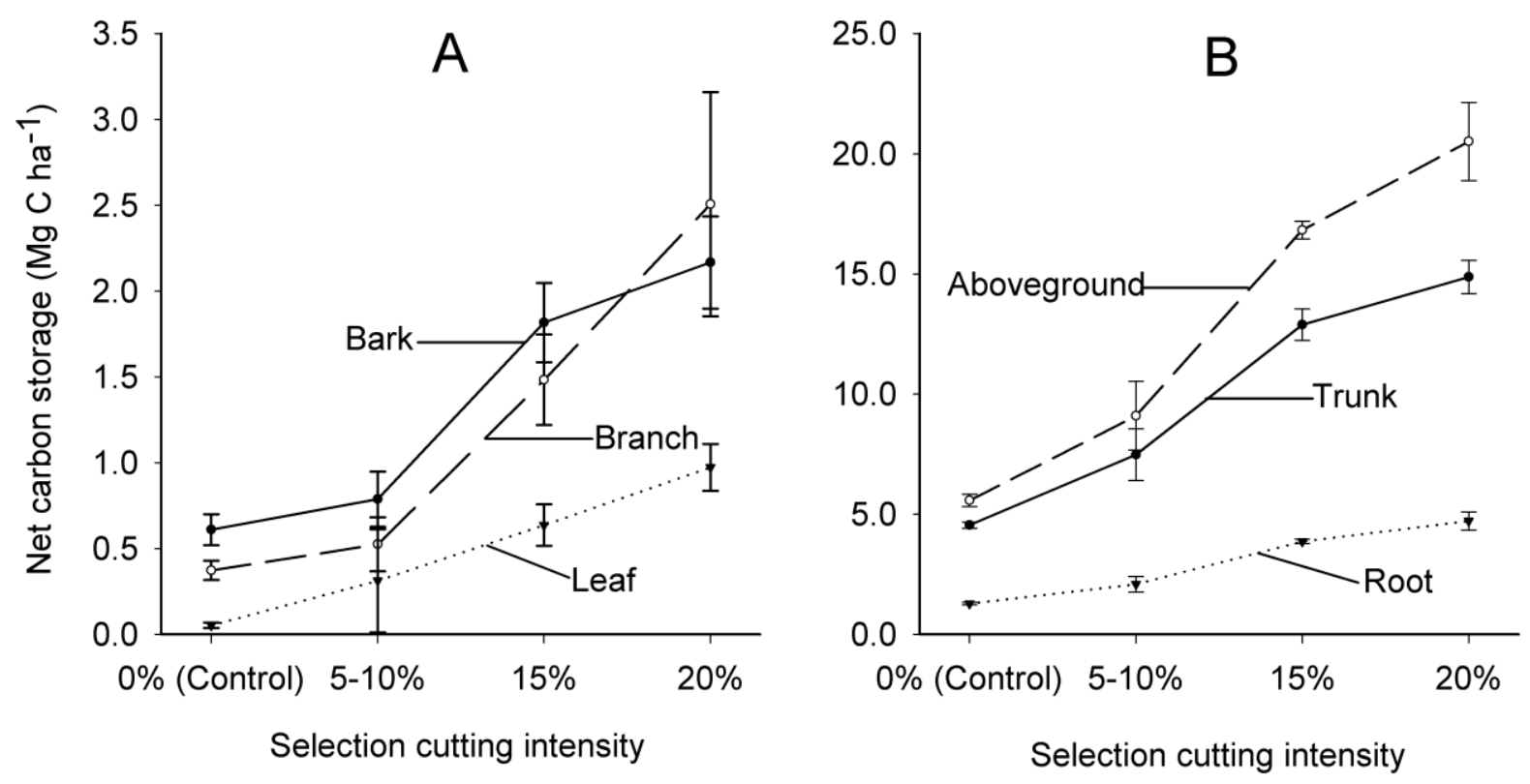

Figure 4. Net increase in carbon storage (mean \pm standard error) for the period 1987-2006 in different selection cutting intensities for different tree components: A) Small fractions (bark, branch and leaf), and B) large fractions (root, trunk and total tree aboveground carbon).

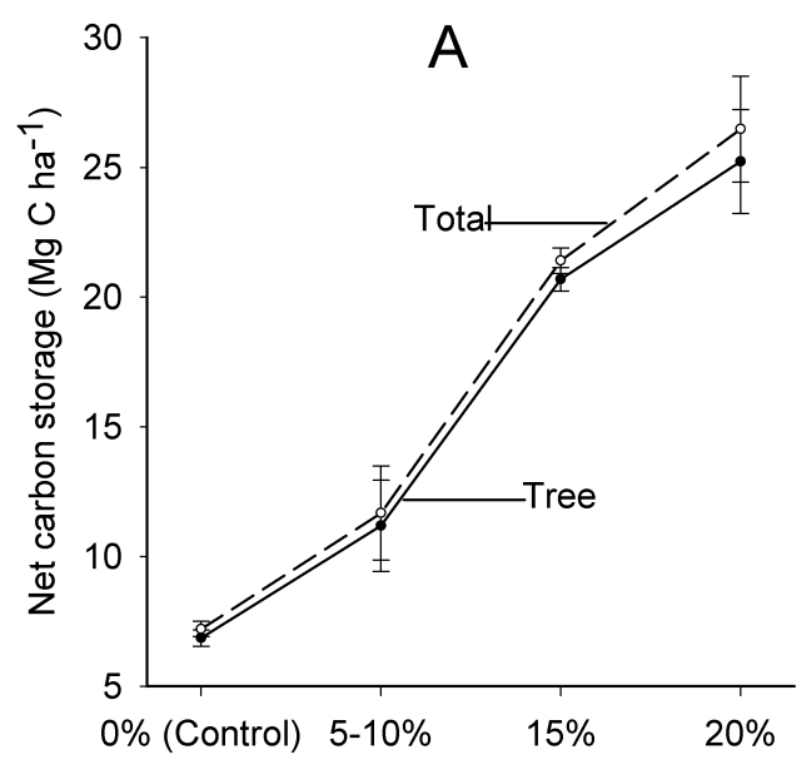

Selection cutting intensity

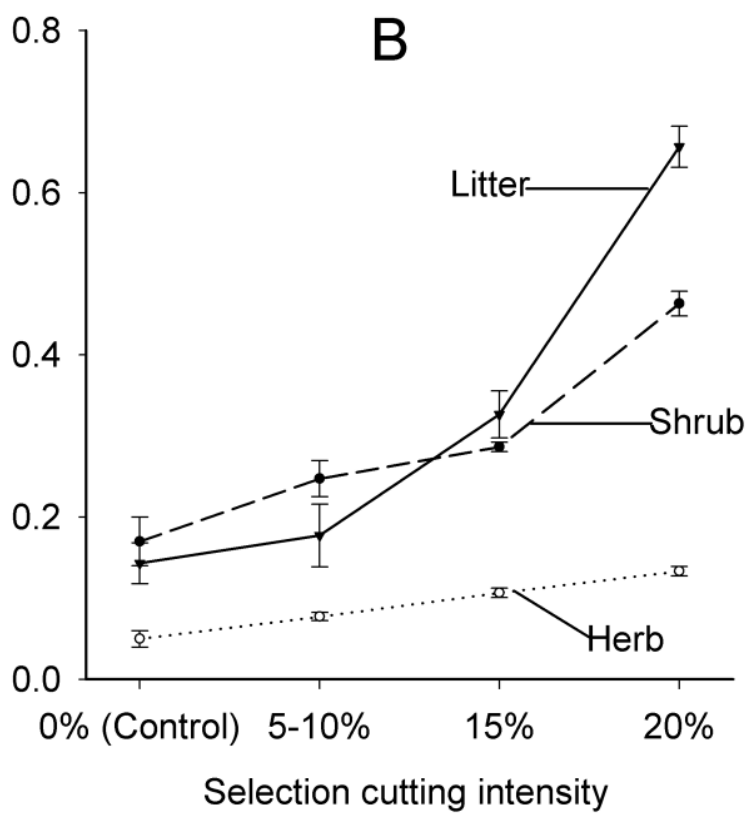

Figure 5. Net increase in carbon storage (mean \pm standard error) for the period 1987-2006 in different selection cutting intensities for different ecosystem components: A) total forest and trees; B) shrub, herb and litter. 
Annex 1. Research design and monitoring schedule. BA: basal area; E: plot establishment; C: selection cutting; M: measurement and inventory.

\begin{tabular}{|c|c|c|c|c|c|c|c|c|c|c|c|c|c|}
\hline \multirow{2}{*}{$\begin{array}{l}\text { Block (area in ha) } \\
\text { Plot }\end{array}$} & \multicolumn{5}{|c|}{ I (95.2) } & \multicolumn{5}{|c|}{ II (110.0) } & \multicolumn{3}{|c|}{ Control (21.0) } \\
\hline & I-1 & $\mathrm{I}-2$ & $\mathrm{I}-3$ & $\mathrm{I}-4$ & $\mathrm{I}-5$ & II-1 & II-2 & II-3 & II-4 & II-5 & $\mathrm{C} 1$ & $\mathrm{C} 2$ & $\mathrm{C} 3$ \\
\hline BA removed $(\%)$ & $10 \%$ & $5 \%$ & $15 \%$ & $15 \%$ & $20 \%$ & $20 \%$ & $5 \%$ & $10 \%$ & $15 \%$ & $20 \%$ & $0 \%$ & $0 \%$ & $0 \%$ \\
\hline Number of subplots & 19 & 23 & 22 & 22 & 26 & 32 & 30 & 35 & 27 & 38 & 30 & 24 & 24 \\
\hline Subplots area (ha) & 0.76 & 0.92 & 0.88 & 0.88 & 1.04 & 1.28 & 1.20 & 1.40 & 1.08 & 1.52 & 1.20 & 0.96 & 0.96 \\
\hline \multicolumn{14}{|l|}{ Calendar of activities } \\
\hline (years) & & & & & & & & & & & & & \\
\hline 1987 & EM & EM & EM & EM & EM & - & - & - & - & - & EM & - & - \\
\hline 1988 & - & - & - & - & - & EM & EM & EM & EM & EM & - & EM & EM \\
\hline 1989 & - & - & - & - & M & - & - & - & - & - & M & - & - \\
\hline 1990 & $\mathrm{CM}$ & $\mathrm{CM}$ & $\mathrm{CM}$ & $\mathrm{CM}$ & $\mathrm{C}$ & $\mathrm{C}$ & $\mathrm{C}$ & $\mathrm{CM}$ & $\mathrm{CM}$ & $\mathrm{CM}$ & - & M & M \\
\hline 1991 & - & - & - & - & - & M & M & - & - & - & - & - & - \\
\hline 1992 & M & M & - & M & M & - & - & - & M & - & M & M & - \\
\hline 1993 & - & - & $\mathrm{M}$ & - & - & - & - & $\mathrm{M}$ & - & $\mathrm{M}$ & - & - & $\mathrm{M}$ \\
\hline 1994 & $\mathrm{M}$ & $\mathrm{M}$ & - & $\mathrm{M}$ & $\mathrm{M}$ & $\mathrm{M}$ & $\mathrm{M}$ & - & $\mathrm{M}$ & - & - & $\mathrm{M}$ & - \\
\hline 1995 & $\mathrm{C}$ & $\mathrm{C}$ & $\mathrm{CM}$ & $\mathrm{C}$ & $\mathrm{C}$ & $\mathrm{C}$ & $\mathrm{C}$ & $\mathrm{CM}$ & $\mathrm{C}$ & $\mathrm{CM}$ & $\mathrm{M}$ & - & $\mathrm{M}$ \\
\hline 1996 & $\mathrm{M}$ & M & - & $\mathrm{M}$ & - & - & - & - & - & - & - & - & - \\
\hline 1997 & - & - & - & - & $\mathrm{M}$ & $\mathrm{M}$ & $\mathrm{M}$ & $\mathrm{M}$ & $\mathrm{M}$ & - & $\mathrm{M}$ & $\mathrm{M}$ & $\mathrm{M}$ \\
\hline 1998 & - & $\mathrm{M}$ & $\mathrm{M}$ & - & - & - & - & - & - & $\mathrm{M}$ & - & - & - \\
\hline 1999 & $\mathrm{M}$ & - & - & $\mathrm{M}$ & - & - & - & - & - & - & $\mathrm{M}$ & $\mathrm{M}$ & $\mathrm{M}$ \\
\hline 2000 & - & - & - & - & $\mathrm{M}$ & $\mathrm{M}$ & $\mathrm{M}$ & $\mathrm{M}$ & $\mathrm{M}$ & - & - & - & - \\
\hline 2001 & $\mathrm{M}$ & $\mathrm{M}$ & $\mathrm{M}$ & $\mathrm{M}$ & - & - & - & - & - & $\mathrm{M}$ & $\mathrm{M}$ & $\mathrm{M}$ & $\mathrm{M}$ \\
\hline 2002 & - & - & - & - & - & - & - & - & - & - & - & - & - \\
\hline 2003 & - & - & - & $\mathrm{M}$ & $\mathrm{M}$ & $\mathrm{M}$ & $\mathrm{M}$ & $\mathrm{M}$ & $\mathrm{M}$ & - & $\mathrm{M}$ & $\mathrm{M}$ & $\mathrm{M}$ \\
\hline 2004 & $\mathrm{M}$ & $\mathrm{M}$ & $\mathrm{M}$ & - & - & - & - & - & - & M & - & - & - \\
\hline 2005 & - & - & - & - & $\mathrm{M}$ & $\mathrm{M}$ & - & - & - & - & - & - & $\mathrm{M}$ \\
\hline 2006 & $\mathrm{M}$ & $\mathrm{M}$ & $\mathrm{M}$ & M & - & - & M & M & $\mathrm{M}$ & M & $\mathrm{M}$ & $\mathrm{M}$ & - \\
\hline
\end{tabular}

